Graziela de Souza QueIRoz Martins

\title{
Avaliação do trauma intracoclear causado pela inserção do feixe de eletrodos do implante coclear via janela redonda em ossos temporais
}

Tese apresentada à Faculdade de Medicina da Universidade de São Paulo para obtenção do título de Doutor em Ciências

Programa de Otorrinolaringologia

Orientador: Prof. Dr. Ricardo Ferreira Bento 


\section{Dados Internacionais de Catalogação na Publicação (CIP)}

Preparada pela Biblioteca da

Faculdade de Medicina da Universidade de São Paulo

Creprodução autorizada pelo autor

Martins, Graziela de Souza Queiroz

Avaliação do trauma intracoclear causado pela inserção do feixe de eletrodos do implante coclear via janela redonda em ossos temporais / Graziela de Souza Queiroz Martins. -- São Paulo, 2014.

Tese(doutorado)--Faculdade de Medicina da Universidade de São Paulo.

Programa de Otorrinolaringologia.

Orientador: Ricardo Ferreira Bento.

Descritores: 1.Implante coclear 2.Implantes cocleares 3.Osso temporal/anatomia \& histologia 4.Osso temporal/cirurgia 5. Janela da cóclea/lesões 6 .Janela da cóclea/cirurgia 7.Perda auditiva neurossensorial 8 .Eletrodos implantados/efeitos adversos 9.Orelha interna 10.Cóclea/lesões 11.Cadáver 12.Humanos 
"São fúteis e cheias de erros as ciências que não nasceram da experimentação, mãe de todo o conhecimento" Leonardo da Vinci (1452-1519) 
Dedico

Aos meus pais, José Octavio e Maria Helena, norte de moral e ética, exemplos pessoais e profissionais. Com esforço e dedicação construíram uma família sólida e unida. Seus valores, presença constante e amor são responsáveis por minhas qualidades, méritos e vitórias.

Ao meu marido Pedro, essa é a nossa tese! Seu apoio aos meus sonhos é o alicerce para eles se tornarem realidade.

Ao meu irmão Frederico, por todas as vezes que me escutou e me levantou. Nossa relação de irmão é a que desejo para meus filhos.

Aos meus filhos Joaquim e Fernando, obrigada por me ensinar o que eu mais amo na vida: ser mãe de vocês. 


\section{AGRADECIMENTOS}

Agradeço...

Ao Prof. Dr. Ricardo Ferreira Bento, Professor Titular da Disciplina de Otorrinolaringologia da FMUSP e orientador desta tese, pelo empreendedorismo e dedicação com os quais comanda este centro de excelência, e pela oportunidade de completar minha formação profissional sob sua tutela, durante os anos de residência, formação especializada e pós-graduação.

Ao Prof. Dr. Rubens Vuono de Brito Neto, Professor Associado da Disciplina de Otorrinolaringologia da FMUSP, pelo apoio e ensinamentos durante o período de residência, especialização e pós-graduação. Pela amizade e conselhos imprescindíveis para meu crescimento pessoal e profissional. Pela confiança em mim depositada permitindo-me fazer parte de sua equipe. Sua capacidade de conciliar competência profissional e dedicação a família são estímulos a todos que o rodeiam.

Ao Prof. Dr. Luiz Ubirajara Sennes, Professor Associado e Coordenador do Programa de Pós-graduação da Disciplina de Otorrinolaringologia da FMUSP, pelos ensinamentos durante o período de residência e pós-graduação. Sua competência profissional e idoneidade são inspiradoras.

Ao Dr. Rui Imamura, médico assistente do Hospital das Clínicas da FMUSP, pelos ensinamentos ilimitados durante o período de residência e pós-graduação. Pela confiança em mim depositada na indicação do meu nome para o curso de Harvard, que despertou meu amor à pesquisa. Pela 
oportunidade de trabalhar na equipe deste profissional exemplo de caráter, dedicação, humildade e competência.

Ao Dr. Ronaldo Frizzarini, médico assistente do Hospital das Clínicas da FMUSP, pela boa vontade em ajudar e pela colaboração imprescindível para a finalização desta tese. Pela sua amizade que amenizou árduos momentos da minha vida profissional e pessoal.

À Dra. Eloisa Maria Mello Santiago Gebrim, médica assistente do serviço de radiologia do Hospital das Clínicas da FMUSP, pela disponibilidade e conhecimento para avaliação radiológica das peças desta tese. Exemplo de médica, pesquisadora e mãe, inspiração para outras médicas, como eu.

À Dra Maria Valeria Goffi Gomes, fonoaudióloga do Grupo de Implante Coclear do Hospital das Clínicas da FMUSP, pelas orientações valiosas no exame de qualificação.

À Sra. Adriana Raquel pelo auxílio e disponibilidade que foram essenciais para a execução deste projeto.

Ao Prof. Dr. Carlos Augusto Pasqualucci, Sr. Nilton Fontes Neuman e aos técnicos do Serviço de Verificação de Óbitos da capital, por contribuírem de maneira tão solícita e ética para o acesso aos ossos temporais utilizados nesta tese.

À Dra. Tatiana Alves Monteiro pelo incentivo durante todas as fases deste trabalho e pelos projetos bem sucedidos que realizamos fora e dentro da vida acadêmica. Por me oferecer diariamente o privilégio de trabalhar com uma amiga. 
À Maria Helena Andreotti de Souza Queiroz, minha melhor amiga, pelas inúmeras vezes que leu e corrigiu estes e todos os outros trabalhos da minha vida.

À Angela Martins Guido Rios pela paciência e talento na confecção dos desenhos desta tese.

À Whitney Boughton pela disponibilidade e excelência na tradução desta tese.

Aos Dr. José Celso Souza e Dr. Roberto Bonanomi pelo privilégio de tê-los como mestres. Seus conselhos e opiniões foram, e sempre serão, muito importantes em minha formação.

Às Dra. Silvia Bona do Nascimento, Dra. Mariana Hausen Pinna e Dra. Andrea Felice dos Santos e aos Dr. Alexandre Nakasato, minha dupla de residência, e Dr. Aquiles Figueiredo Leal, minha dupla de Fellow, amigos com os quais dividi meus sonhos e projetos. Compartilhamos experiências que foram fundamentais para a confecção deste trabalho.

Ao Dr. Alexandre Beraldo Ordones, Dr. Francisco das Chagas Cabral Junior e Dr. Ricardo Dourado Alves que sempre se mostraram disponíveis em me auxiliar na execução deste estudo.

Aos amigos e médicos assistentes do grupo de otologia do Hospital das Clínicas da FMUSP pelo companheirismo, aprendizado e convivência prazerosa.

À Maria Márcia Alves, Maria Marilede Alves e Lucivania Lima da Silva pela disponibilidade e carinho dispensados durante toda a minha formação no Departamento de Otorrinolaringologia da FMUSP. 
Ao Guilherme, Eduarda, Joana e Antônio fontes de motivação para lutar por um futuro melhor. Obrigada por me permitir crescer com vocês.

A todos os pacientes com quem convivi durante os anos da minha formação que, em meio ao sofrimento, contribuem com a ciência e aprendizado, meu respeito e gratidão.

Às instituições FAPESP, CNPq e FORL. 


\section{APOIO FINANCEIRO}

FAPESP - Fundação de Amparo à Pesquisa do Estado de São Paulo, aprovou e financia a execução deste projeto.

Projeto número: 11/20095-0

CNPq - Conselho Nacional de Desenvolvimento Científico e Tecnológico, aprovou bolsa de estudo para este projeto. 


\section{SUMÁRIO}

Lista de Siglas

Lista de Abreviaturas

Lista de Símbolos

Lista de Figuras

Lista de Tabelas

Resumo

Abstract

1 INTRODUÇÃO

01

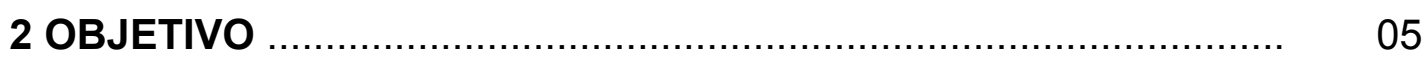

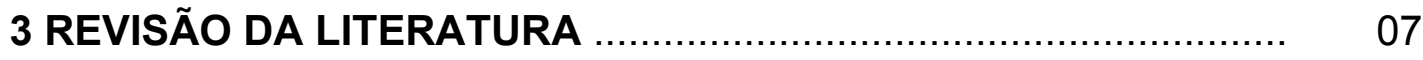

3.1 Preservação da audição residual após cirurgia do implante coclear

3.1.1 Vantagens da preservação da audição residual e da ausência de trauma intracoclear em pacientes que não utilizam estimulação eletroacústica

08

3.2 Trauma intracoclear

3.2.1 Associação entre trauma intracoclear e perda da audição residual

3.2.2 Associação entre trauma intracoclear e preservação da audição residual com fibrose e neoformação óssea ....

3.2.3 Associação entre trauma intracoclear e degeneração retrógrada 13

3.2.4 Associação entre trauma intracoclear e tecnologias futuras

3.3 Cirurgia atraumática - inserção do feixe de eletrodos do implante coclear

3.4 Características anatômicas da janela redonda relevantes para a inserção do feixe de eletrodos do implante coclear 
4 MÉTODOS …................................................................ 20

4.1 Aspectos éticos da pesquisa ............................................ 21

4.2 Material ......................................................................... 21

4.3 Aleatorização ............................................................. 22

4.4 Preparo dos ossos temporais para inserção do feixe de eletrodos do implante coclear ........................................................... 23

4.5 Feixe de eletrodos ......................................................... 30

4.6 Preparo dos ossos temporais para análise histológica ................ 31

4.7 Análise estatística ........................................................... 37

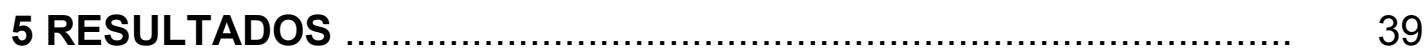

5.1 Descrição dos ossos temporais ......................................... 40

5.2 Análise das tomografias computadorizadas ............................... 41

5.3 Análises histológicas ......................................................... 42

6 DISCUSSÃO ...................................................................... 52

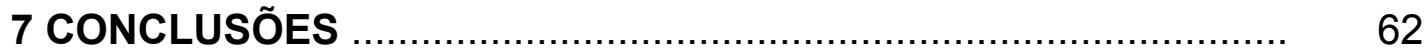

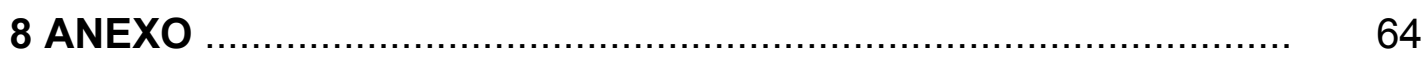

Anexo A - Ficha de Protocolo .................................................. 65

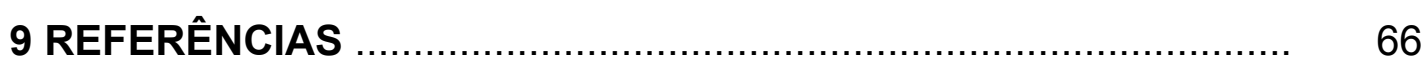
APÊNDICES

Apêndice 1 - Carta de aprovação da Comitê de Ética em Pesquisa da FMUSP

Apêndice 2 - Adendo ao Protocolo do Comitê de Ética em Pesquisa da FMUSP

Apêndice 3 - Aprovação no Departamento de Radiologia da FMUSP 


\section{LISTA DE SIGLAS}

$\begin{array}{ll}\text { CNPq } & \begin{array}{l}\text { Conselho Nacional de Desenvolvimento Científico e } \\ \text { Tecnológico }\end{array} \\ \text { EUA } & \text { Estados Unidos da América } \\ \text { FAPESP } & \begin{array}{l}\text { Fundação de Amparo a Pesquisa do Estado de São Paulo } \\ \text { do inglês Food and Drug Administration }\end{array} \\ \text { FDA } & \text { Faculdade de Medicina da Universidade de São Paulo } \\ \text { FMUSP } & \text { Fundação Otorrinolaringologia } \\ \text { FORL } & \text { Hospital das Clínicas da Faculdade de Medicina da } \\ \text { HC-FMUSP } & \text { Universidade de São Paulo } \\ \text { OMS } & \text { Organização Mundial de Saúde } \\ \text { USP } & \text { Universidade de São Paulo }\end{array}$




\section{LISTA DE ABREVIATURAS}

$\begin{array}{ll}\text { AAS } & \text { Aparelho de Amplificação Sonora } \\ \text { DP } & \text { Desvio Padrão } \\ \text { Dr. } & \text { Doutor } \\ \text { EEA } & \text { Estimulação Eletroacústica } \\ \text { Ed. } & \text { Edição } \\ \text { EOAPD } & \text { Emissões Otoacústicas por produtos de distorção } \\ \text { et al. } & \text { do latim et alii (e outros) } \\ \text { IC } & \text { Implante Coclear } \\ \text { ICs } & \text { Implantes Cocleares } \\ \text { Inc. } & \text { do inglês Incorporation (Incorporação) } \\ \text { JR } & \text { Janela Redonda } \\ \text { máx. } & \text { máximo } \\ \text { mín. } & \text { mínimo } \\ \text { n } & \text { quantidade de pacientes } \\ \text { p. } & \text { página } \\ \text { PEATE } & \text { Potencial Evocado Auditivo de Tronco Encefálico } \\ \text { Prof. } & \text { Professor } \\ \text { SPL } & \text { do inglês Sound Pressure Level (Nível de Pressão Sonora) } \\ \text { SPSS } & \text { Statistical Package for Social Science } \\ \text { Supl. } & \text { Suplemento } \\ \text { SVO } & \text { Serviço de Verificação de Óbito } \\ \text { TC } & \text { Tomografia Computadorizada } \\ \text { TCs } & \text { Tomografias Computadorizadas } \\ \text { 15x a 120x } & \text { aumento de 15 a 120 vezes }\end{array}$




\section{LISTA DE SÍMBOLOS}

$\begin{array}{ll}\mathrm{C} & \text { Celsius } \\ \mathrm{C} & \text { do inglês copyright (direito autoral) } \\ \mathrm{Hz} & \text { decibel } \\ \mathrm{mm} & \text { Hertz } \\ \mathrm{mm}^{2} & \text { milímetro } \\ \mathrm{p} & \text { milímetro quadrado } \\ \mu \mathrm{m} & \text { nível descritivo } \\ \circ & \text { micrometro } \\ \mathrm{a} & \text { indicador ordinal masculino } \\ 0 & \text { indicador ordinal feminino } \\ = & \text { grau } \\ { }_{\circledast} & \text { igual a } \\ > & \text { marca registrada } \\ \pm & \text { maior que } \\ \leq & \text { mais ou menos } \\ < & \text { menor ou igual } \\ \% & \text { menor que } \\ & \text { porcento }\end{array}$




\section{LISTA DE FIGURAS}

Figura 1 Fluxograma de estudo dos ossos temporais

Figura 2 Osso temporal após descongelamento até a temperatura ambiente

Figura 3 Osso temporal após remoção de estruturas anexas .....

Figura 4 Osso temporal fixado em posição cirúrgica, sob iluminação do microscópio

Figura 5 Timpanomastoidectomia com timpanotomia posterior ampla

Figura 6 Visualização, através da timpanotomia posterior, do nicho da janela redonda com identificação de falsa membrana

Figura 7 Visualização, através da timpanotomia posterior, da membrana da janela redonda parcialmente recoberta por projeções ósseas

Figura 8 Visualização, através da timpanotomia posterior, da membrana da janela redonda após remoção das projeções ósseas

Figura 9 Abertura no quadrante anterossuperior da membrana da janela redonda

Figura 10 Inserção do feixe de eletrodos através da abertura no quadrante anterossuperior da membrana da janela redonda

Figura 11 Feixe de eletrodos EVO ${ }^{\circledR}$ (Neurelec, Vallauris, França/ Oticon Medical, Gothenburg, Suécia)

Figura 12 Recipientes com ossos temporais imersos em etanol sobre a mesa agitadora Orbital Shake ${ }^{\circledR}$ (Logen Scientific, Brasil) 
Figura 13 Osso temporal imerso em resina epóxi, dentro do dessecador submetido a vácuo (Bomba Vacuubrand PC3001 basic $^{\circledR}$ - Vacuubrand, Wertheim, Alemanha) ...

Figura 14 Osso temporal embutido em resina epóxi (Resina Epofix ${ }^{\circledR}$ - Struers, Ballerup, Dinamarca)

Figura 15 Ossos temporais embutidos em resina epóxi, posicionados para ser realizada a tomografia computadorizada

Figura 16 Máquina polidora (LaboPol- $5^{\circledR}$ - Struers, Ballerup, Dinamarca)

Figura 17 Estereomicroscópio (Discovery V8 ${ }^{\circledR}$ - Carl Zeiss, Göttingen, Alemanha) acoplado à câmara digital (AxionCam ERc $5 s^{\circledR}$ - Carl Zeiss, Göttingen, Alemanha) e computador com programa AxionVision ${ }^{\circledR}$ (Carl Zeiss, Göttingen, Alemanha)

Figura 18 Osso temporal sob iluminação do estereomicroscópio (Discovery V8 ${ }^{\circledR}$ - Carl Zeiss, Göttingen, Alemanha) ...... 36

Figura 19 Representação diagramática dos segmentos da cóclea

Figura 20 Imagem de tomografia computadorizada com visualização do feixe de eletrodos intracoclear

Figura 21 Visualização da membrana da janela redonda (seta vermelha), determinando o limite inicial do segmento 1 (Estereomicroscópio Discovery $\mathrm{V}^{\circledR}$ - Carl Zeiss, Göttingen, Alemanha. Aumento de 30x. Coloração azul de toluidina O)

Figura 22 Identificação dos segmentos 1 e 4 . Modíolo visualizado mais profundo à superfície da peça (Estereomicroscópio Discovery V8 ${ }^{\circledR}$ - Carl Zeiss, Göttingen, Alemanha. Aumento de 15x. Coloração azul de toluidina O) 
Figura 23 Identificação dos segmentos 1,3 e 5 . Inicio da visualização do modíolo na superfície da peça, definindo início dos segmentos 3 e 5 (Estereomicroscópio Discovery V8 ${ }^{\circledR}$ - Carl Zeiss, Göttingen, Alemanha. Aumento de 15x. Coloração azul de toluidina O)

Figura 24 Visualização dos segmentos 1, 3 e modíolo (Estereomicroscópio Discovery V8 ${ }^{\circledR}$ - Carl Zeiss, Göttingen, Alemanha. Aumento de 15x. Coloração azul de toluidina O)

Figura 25 Visualização do início do segmento 2. O modíolo não é mais visualizado (Estereomicroscópio Discovery $V 8^{\circledR}$ Carl Zeiss, Göttingen, Alemanha. Aumento de 15x. Coloração azul de toluidina O)

Figura 26 Feixe de eletrodos posicionado na escala timpânica. Estruturas intracocleares preservadas (Grau 0 ) (Estereomicroscópio Discovery $\mathrm{V}^{\circledR}$ - Carl Zeiss, Göttingen, Alemanha. Aumento de 60x. Coloração azul de toluidina O)

Figura 27 Feixe de eletrodos na escala timpânica causando discreta elevação da membrana basilar (Grau 1) (Estereomicroscópio Discovery $\mathrm{V}^{\circledR}$ - Carl Zeiss, Göttingen, Alemanha. Aumento de 120x. Coloração azul de toluidina O)

Figura 28 Identificação de ruptura da membrana basilar (Grau 2) (Estereomicroscópio Discovery V8 ${ }^{\circledR}$ - Carl Zeiss, Göttingen, Alemanha. Aumento de 94x. Coloração azul de toluidina O) 
Figura 29 Deslocamento do feixe de eletrodos da escala timpânica para escala vestibular (Grau 3) (Estereomicroscópio Discovery $\mathrm{V} 8^{\circledR}$ - Carl Zeiss, Göttingen, Alemanha. Aumento de 15x. Coloração azul de toluidina O)

Figura 30 Identificação de fratura da lâmina espiral óssea (Grau 4) (Estereomicroscópio Discovery $V 8^{\circledR}$ - Carl Zeiss, Göttingen, Alemanha. Aumento de 60x. Coloração azul de toluidina O) 


\section{LISTA DE TABELAS}

Tabela 1 Classificação do trauma coclear após inserção do feixe de eletrodos

Tabela 2 Dimensões dos feixes de eletrodos EVO ${ }^{\circledR}$ (Neurelec, Vallauris, França/Oticon Medical, Gothenburg, Suécia)

Tabela 3 Descrição das características dos ossos temporais do grupo $1(n=13)$ e grupo $2(n=12)$.

Tabela 4 Quantidade de superfícies por peça em cada um dos grupos de ossos temporais e resultados dos testes comparativos

Tabela 5 Descrição da presença de trauma intracoclear, considerando trauma positivo qualquer grau diferente de zero, em cada um dos segmentos nos dois grupos e resultados dos testes de associação

Tabela 6 Descrição da presença de trauma intracoclear, considerando trauma positivo os graus 2,3 e 4 em cada um dos segmentos nos dois grupos e resultados dos testes de associação

Tabela 7 Descrição do grau de trauma em cada um dos segmentos nos dois grupos e resultado dos testes comparativos 


\section{RESUMO}

Martins GSQ. Avaliação do trauma intracoclear causado pela inserção do feixe de eletrodos do implante coclear via janela redonda em ossos temporais [tese]. São Paulo: Universidade de São Paulo, Faculdade de Medicina; 2014.

INTRODUÇÃO: A ampliação dos critérios de indicação para cirurgia do implante coclear e os benefícios da preservação da audição residual no pósoperatório estimularam 0 desenvolvimento de técnicas cirúrgicas atraumáticas. Minimizar os traumas intracocleares durante a inserção do feixe de eletrodos do implante coclear é um passo fundamental para este intuito. O objetivo deste trabalho é avaliar se o trauma intracoclear é diferente quando o feixe de eletrodos do implante coclear é inserido através do quadrante anterossuperior ou anteroinferior da membrana da janela redonda. MÉTODOS: Vinte e cinco ossos temporais frescos de cadáveres humanos foram submetidos à timpanomastoidectomia padrão. Após exposição adequada da membrana da janela redonda, em metade dos ossos o feixe de eletrodos do implante coclear foi inserido via quadrante anterossuperior da membrana da janela redonda, e na outra metade via quadrante anteroinferior. Os ossos temporais foram desidratados e embebidos em epóxi, com o feixe de eletrodos in situ. As peças foram serialmente polidas, tingidas e visualizadas por meio de estereomicroscópio para avaliar o trauma intracoclear causado pela inserção do feixe de eletrodos. As imagens foram fotografadas. RESULTADOS: Em treze ossos temporais o feixe de eletrodos do implante coclear foi inserido via quadrante anterossuperior da membrana da janela redonda, e em doze ossos via quadrante anteroinferior. Obteve-se 372 superfícies. As análises histológicas revelaram diferentes graus de traumas às estruturas intracocleares. Os resultados mostraram que a inserção do feixe de eletrodos via quadrante anterossuperior ou anteroinferior acarretam a mesma frequência de trauma intracoclear. CONCLUSÕES: A presença de trauma intracoclear e a severidade dos traumas ocorridos no tocante à inserção do feixe de eletrodos de implante coclear pelo quadrante anterossuperior e anteroinferior da membrana da janela redonda não apresentou diferença estatisticamente significativa. Observou-se, porém, maior facilidade para exposição cirúrgica do quadrante anterossuperior em relação ao quadrante anteroinferior.

DESCRITORES: Implante coclear; Implantes cocleares; Osso temporal/anatomia \& histologia; Osso temporal/cirurgia; Janela da cóclea/lesões; Janela da cóclea/cirurgia; Perda auditiva neurossensorial; Eletrodos implantados/efeitos adversos; Orelha interna; Cóclea/lesões; Cadáver; Humanos. 


\begin{abstract}
Martins GSQ. Assessment of intracochlear trauma caused by insertion of cochlear implant electrode array via round window in temporal bones. [thesis]. São Paulo: Universidade de São Paulo, Faculdade de Medicina; 2014.
\end{abstract}

INTRODUCTION: The expansion of the indication criteria for cochlear implant surgery and the benefits of preserving residual hearing postoperatively have stimulated the development of atraumatic surgeries. Minimizing the intracochlear traumas during the electrodes insertion is a critical step for this aim. The objective of this study is to assess whether there is a difference in intracochlear trauma when the cochlear implant electrode array is inserted through the anterior-superior or anterior-inferior quadrants of the round window membrane. METHODS: Twenty-five fresh human temporal bones were submitted to standard tympanomastoidectomy. After adequate exposure of the round window membrane, in half of the bones the cochlear implant electrode array was inserted via anterior-superior quadrant of round window membrane and in the other half via anterior-inferior quadrant. The temporal bones were dehydrated and embedded in epoxy with the electrodes array in situ. The specimens were serially polished, stained and viewed through a stereomicroscope to assess the intracochlear trauma caused by insertion of the electrode array. Resulting images were documented. RESULTS: In thirteen temporal bones the cochlear implant electrode array was inserted via anterior-superior quadrant of round window membrane and in twelve bones via anterior-inferior quadrant. Three hundred and seventy two surfaces were obtained. Histological examinations revealed varying degrees of damage to the intracohlear structures. The results showed that the insertion of the electrode array via anterior-superior or anterior-inferior quadrant lead to the same frequency of intracochlear trauma. CONCLUSIONS: The presence of intracochlear trauma and severity of traumas regarding the insertion of cochlear implant electrode array via anterior-superior and via anterior-inferior quadrant of the round window membrane showed no statistically significant difference. However, it was observed that surgical exposure of anterior-superior quadrant was easier than surgical exposure of anterior-inferior quadrant.

Descriptors: Cochlear implantation; Cochlear implants; Temporal bone/anatomy \& histology; Temporal bone/surgery; Round window, ear/injuries; Round window, ear/surgery; Hearing loss, sensorioneural; Electrodes, implanted/adverse effects; Ear, inner; Cochlea/injuries; Cadaver; Humans. 
1 INTRODUÇÃO 


\section{INTRODUÇÃO}

A perda de audição é uma deficiência que pode comprometer a personalidade, os relacionamentos e todo o estilo de vida de uma pessoa. Pode levar à dificuldade de comunicação, isolamento social e até risco à integridade física ${ }^{1}$.

Alguns dados ilustram o impacto mundial da perda auditiva. Segundo a Organização Mundial de Saúde (OMS), 278 milhões de pessoas, em todo o mundo, apresentam perda de audição bilateral moderada ou mais acentuada $^{2}$. No Brasil, a perda de audição não necessita ser notificada compulsoriamente aos órgãos públicos o que dificulta a estimativa de sua incidência. Em um estudo conforme os protocolos da OMS, realizado por Baraky et al. $^{3}$, 2011, em Juiz de Fora, Minas Gerais, Brasil, os autores encontraram prevalência absoluta de perda de audição incapacitante em $6,7 \%$ da população analisada. Quando consideradas apenas crianças com idades abaixo de 15 anos, estes valores foram reduzidos para $2,5 \%$. No entanto, para idades acima dos 55 anos, a prevalência de perda de audição incapacitante foi de $11,68 \%$.

Entre as formas de reabilitação, o implante coclear (IC) é amplamente aceito como método efetivo para pacientes com perda de audição neurossensorial severa ou profunda bilateral. Os implantes cocleares (ICs) transformam estímulos sonoros em correntes elétricas, que por meio de um 
feixe de eletrodos inserido na cóclea, estimulam fibras nervosas, independente da função das células ciliadas.

A evolução dos ICs, nos últimos 30 anos, é considerada uma das histórias de sucesso da medicina moderna. Os resultados alcançados em pacientes implantados são notáveis e muito melhores do que aqueles, até o momento, alcançados por qualquer outro tipo de prótese neural ${ }^{4}$. Estes resultados têm incentivado a ampliação dos critérios de seleção para $\mathrm{IC}^{5}$. Assim, é crescente a quantidade de candidatos à IC com audição residual significativa, e, como consequência, diversos estudos estão sendo realizados na tentativa de preservar a audição residual destes pacientes no pós-operatório.

Estudos histológicos de cócleas implantadas com feixes de eletrodos de ICs demonstraram a presença de trauma de diferentes estruturas como a membrana basilar, o ligamento espiral e a lâmina espiral óssea ${ }^{6,7}$. O trauma intracoclear durante a cirurgia de IC é um dos fatores associado à perda de audição residual ${ }^{8-10}$. Trabalhos anteriores permitiram demonstrar a possibilidade de inserção do feixe de eletrodos sem traumas intracocleares significativos, utilizando técnicas cirúrgicas atraumáticas ${ }^{9,11-14}$.

Entre os passos da cirurgia atraumática a inserção do feixe de eletrodos é um dos mais estudados. O feixe pode ser inserido na cóclea mediante a confecção de um pequeno orifício denominado cocleostomia ou pela janela redonda (JR). Segundo Banfai $^{15}$, em 1978, a primeira via utilizada para inserção do feixe de eletrodos do IC foi a JR. Com o surgimento de feixes de eletrodos mais longos, com mais eletrodos, mais 
grossos e pouco maleáveis a introdução por esta via tornou-se inviável. Passou-se, então, a realizar a cocleostomia na região anterior da JR. Com o decorrer dos anos, o desenvolvimento de eletrodos cada vez mais finos e maleáveis permitiu que a inserção pela JR voltasse a ser viável ${ }^{16}$. A possibilidade de duas vias de inserção incentivou diversos estudos a compararem-nas ${ }^{17-21}$.

Ao contrário da cocleostomia, sobre a qual existem inúmeros trabalhos, nos quais foi observado se o trauma intracoclear varia conforme a sua localização, até o momento, não foram identificados estudos que comparem se o trauma intracoclear apresenta variação, quando o feixe de eletrodos é inserido via diferentes quadrantes da JR. 
2 OBJETIVO 


\section{OBJETIVO}

Avaliar se o trauma intracoclear é diferente, quando o feixe de eletrodos do implante coclear é inserido através do quadrante anterossuperior ou anteroinferior da membrana da janela redonda. 
3 REVISÃO DA LITERATURA 


\section{REVISÃO DA LITERATURA}

\subsection{Preservação da audição residual após cirurgia do implante coclear}

A possibilidade de preservação da audição residual, após cirurgia de IC, não é uma descoberta recente. Ni et al. ${ }^{22}$, em 1992, e Xu et al. ${ }^{23}$, em 1997, reportaram a manutenção de limiares próximos aos normais, no potencial evocado auditivo de tronco encefálico (PEATE) de animais implantados.

Kiefer et al. ${ }^{24}$, em 2004, em um estudo com 14 pacientes, obtiveram alta taxa de preservação da audição no pós-operatório. Doze destes pacientes tiveram a audição, pelo menos, parcialmente preservada. A média da diminuição dos limiares foi de $10 \mathrm{~dB}, 15 \mathrm{~dB}, 17,5 \mathrm{~dB}$ e $5 \mathrm{~dB}$, nas frequências de $125 \mathrm{~Hz}, 250 \mathrm{~Hz}, 500 \mathrm{~Hz}$ e $1000 \mathrm{~Hz}$, respectivamente.

As porcentagens de preservação da audição são muito variáveis. Pode-se encontrar valores de preservação total e parcial da audição entre $8 \%$ e $68 \%$, e entre $83 \%$ e $100 \%$, respectivamente ${ }^{25-27}$.

3.1.1 Vantagens da preservação da audição residual e ausência de trauma intracoclear em pacientes que não utilizam estimulação eletroacústica

Gstoettner et al. ${ }^{28}$, em 2004, avaliaram a preservação da audição em 21 pacientes com IC. Em 18 pacientes ocorreu a preservação da audição residual em frequências baixas. Em 13 pacientes ocorreu a preservação 
completa da audição residual. Os resultados dos testes de discriminação da fala demonstraram um grande benefício da estimulação eletroacústica (EEA) em relação ao IC ou aparelhos de amplificação sonora (AAS), usados isoladamente. Além disso, os autores citaram que mesmo com a utilização do IC isolado, estes pacientes apresentaram resultados melhores do que os de outros pacientes similares, mas sem audição residual. Os autores creditaram este fato à utilização de técnicas cirúrgicas atraumáticas que aumentam as chances de preservação de estruturas neurais.

Balkany et al. $^{9}$, em 2006, em um estudo prospectivo com 28 pacientes, descreveram a preservação do limiares tonais em $80 \%$ dos pacientes implantados. Porém, a preservação da audição residual não foi associada aos melhores resultados com o IC.

Contrariamente ao estudo anterior, Carlson et al. ${ }^{10}$, em 2011, avaliaram 126 pacientes implantados com feixe de eletrodos convencional e técnica cirúrgica atraumática. Em 55\% dos pacientes houve preservação da audição. Nestes pacientes o reconhecimento de fala no pós-operatório, com a utilização de estimulo elétrico isolado, foi significativamente maior do que nos pacientes que perderam completamente a audição residual.

Verbist et al. ${ }^{29}$, em 2009, citaram que, mesmo em pacientes com perda de audição profunda, traumas intracocleares, particularmente aqueles que envolvem ruptura da membrana basilar, podem gerar prejuízos indesejáveis ao modificar a combinação da tonotopia do órgão de Corti e do feixe de eletrodos. 


\subsection{Trauma intracoclear}

Eshraghi et al. ${ }^{30}$, em um estudo com 15 ossos temporais, analisaram a posição do feixe de eletrodos e o trauma intracoclear após a cirurgia do IC. Apoiados em suas observações, formularam uma escala numérica, de zero a quatro, para classificar a severidade do trauma intracoclear inicial causado pela inserção do feixe de eletrodos do IC (Tabela 1).

Tabela 1 - Classificação do trauma coclear após inserção do feixe de eletrodos

\begin{tabular}{ll}
\hline \hline Grau & Alteração histológica \\
\hline 0 & Ausência de trauma $^{1}$ \\
1 & Elevação da membrana basilar \\
2 & $\begin{array}{l}\text { Ruptura da membrana basilar } \\
3\end{array}$ \\
& $\begin{array}{l}\text { Destocamento do feixe de eletrodos para dentro da escala } \\
\text { Eratura da lâmina espiral óssea ou modíolo ou ruptura na } \\
\end{array}$ \\
\hline \hline
\end{tabular}

FONTE: Eshraghi et al., $2003^{30}$

${ }^{1}$ Possibilidade de trauma a nível molecular

3.2.1 Associação entre trauma intracoclear e perda da audição residual

Simmons ${ }^{31}$ cita que rupturas da membrana basilar, mesmo que de tamanho reduzido podem alterar o audiograma não apenas nas frequências 
da região do trauma. Isso ocorre, pois tais rupturas levam à mistura da endolinfa e perilinfa, e alteram o gradiente de íons nos líquidos cocleares. Por causa do fluxo endococlear, essa mistura se espalha por toda a cóclea e causa alterações em áreas distantes da lesão. $O$ autor denomina este fenômeno como síndrome da ruptura da dupla membrana. Segundo Zenner $^{32}$, a mistura de endolinfa e perilinfa resulta no aumento da concentração de íons de potássio na perilinfa, o que despolariza as células ciliadas e prejudica as funções cocleares.

Em 2005, Eshraghi et al. ${ }^{33}$ realizaram um estudo com 21 orelhas de ratos. Os ratos foram divididos em três grupos: Grupo 1: grupo controle com sete ratos; Grupo 2: sete ratos nos quais foi realizada apenas a abertura da JR, sem inserção do feixe de eletrodos; e, Grupo 3: sete ratos nos quais foi feita a abertura da JR seguida da inserção do feixe de eletrodos. A audição dos animais foi avaliada mediante testes objetivos (Emissões Otoacústicas por produtos de distorção (EOAPD) e PEATE). Os testes aplicados aos Grupos 1 e 2 não apresentaram alterações, enquanto no Grupo 3 ocorreu aumento progressivo dos limiares e diminuição da amplitude das ondas no PEATE e diminuição progressiva da amplitude nas EOAPD.

Balkany et al. $^{9}$, em 2006, propuseram o uso dos limiares tonais no pós-operatório de IC como um marcador substituto (surrogate endpoint) da extensão do trauma intracoclear.

Em 2010, Campbell et al. ${ }^{34}$ realizaram inserções traumáticas em 18 orelhas de gerbilos. Mediante observação por meio de microendoscópio, para acompanhar a inserção e identificar os locais de impacto do feixe de 
eletrodos dentro da cóclea, os autores conseguiram correlacionar mudanças em testes eletrofisiológicos com o grau e localização do trauma intracoclear.

Em 2011, segundo Carlson et al. ${ }^{10}$, como o trauma direto ou indireto gerado pelo feixe de eletrodos é a causa principal da perda da audição residual, é possível estimar a extensão do trauma intracoclear de acordo com as alterações dos limiares tonais no pós-operatório.

3.2.2 Associação entre trauma intracoclear e preservação da audição residual com fibrose e neoformação óssea

Choi e Ohhalai ${ }^{35}$, em 2005, utilizaram um protótipo de cóclea e descreveram que, a presença de fibrose no giro basal da cóclea altera a vibração da porção apical da membrana basilar, interferindo nas frequências baixas da audição residual.

Glueckert et al. ${ }^{36}$, em 2005, citaram como desvantagens da fibrose intracoclear a necessidade de mais energia para estimulação elétrica das células do gânglio espiral, e o risco de, durante um reimplante, o tecido fibrótico ser empurrado para regiões mais apicais, impedindo a inserção profunda do feixe de eletrodos.

Somdas et al. ${ }^{37}$, em 2007, avaliaram, por meio de reconstrução 3D, a presença de neoformação óssea e fibrose, em sete ossos temporais de pacientes que foram implantados durante suas vidas. As regiões de maior concentração de neoformação óssea e fibrose foram o giro basal da cóclea, a região da cocleostomia e a porção ascendente do giro basal. São as mesmas regiões citadas no estudo de Nadol et al. ${ }^{7}$, em 2001, sugerindo que 
o trauma cirúrgico seja o fator desencadeante. Os autores ainda descreveram que os ossos com menos trauma intracoclear foram os que apresentaram menor quantidade de fibrose e neoformação óssea.

Em 2012, Radeloff et al. ${ }^{38}$ gravaram o microfonismo coclear durante a cirurgia de IC em seis pacientes com audição residual. Quatro pacientes apresentaram deterioração da audição após uma semana da cirurgia. Os autores sugeriram que a perda da audição residual não está relacionada somente ao trauma direto pelo IC, mas também aos fatores secundários, como resposta inflamatória e proliferação de fibrose.

3.2.3 Associação entre trauma intracoclear e degeneração retrógrada

Xu et al. ${ }^{23}$, em 1997, descreveram o padrão de perda de células do gânglio espiral como reflexo da perda das células periféricas, sugerindo que, uma inserção traumática do feixe de eletrodos pode agravar a degeneração de elementos neurais.

Leake et al. $^{39}$, em 1999, em um estudo com animais, descreveram que traumas intracocleares, mesmo que leves, causados pela inserção do feixe de eletrodos resultam em diminuição da densidade neural no gânglio espiral, e que a extensão e gravidade do trauma podem definir a extensão da perda celular ganglionar.

Khan et al. ${ }^{40}$, em 2005, compararam a contagem de células do gânglio espiral da orelha implantada e da orelha não implantada, de 11 ossos temporais de pacientes que durante a vida foram implantados 
unilateralmente. Os resultados mostraram que a contagem de células entre as duas orelhas não foi significativamente diferente nos primeiros $22 \mathrm{~mm}$ da cóclea. No entanto, na região apical ao feixe de eletrodos, a contagem de células foi menor na orelha implantada quando comparada com a orelha não implantada. A hipótese levantada pelos autores, é que o trauma causado pela inserção do feixe de eletrodos causa degeneração retrógrada das células do gânglio espiral, mas que esta degeneração é inibida nos segmentos proximais pela estimulação neural proporcionada pelo IC.

3.2.4 Associação entre trauma intracoclear e tecnologias futuras

Segundo Verbist et al. ${ }^{29}$, é necessário levar em consideração que muitos candidatos à IC são crianças ou adolescentes, e que apesar dos aparelhos atuais serem desenvolvidos para funcionar por muitos anos, espera-se que estes pacientes jovens sejam submetidos a cirurgias revisionais em algum momento de suas vidas. Cirurgias futuras serão mais complicadas se a anatomia da cóclea estiver modificada por causa de traumas locais causados na primeira cirurgia. Os autores lembram que tecnologias em desenvolvimento, por exemplo, terapias com células-tronco, talvez necessitem de estruturas intracocleares intactas para a sua utilização.

Para Helbig et al. ${ }^{41}$, a importância de uma cirurgia menos traumática é obvia, quando se considera a estimativa de que as crianças, atualmente implantadas, serão reimplantadas três a quatro vezes durante suas vidas. 


\subsection{Cirurgia atraumática - inserção do feixe de eletrodos do implante coclear}

Lehnhardt ${ }^{42}$, em 1993, descreveu a técnica cirúrgica atraumática de IC. Nos anos subsequentes, a técnica descrita sofreu modificações e complementações por vários autores.

Dentre os passos da cirurgia atraumática, a inserção do feixe de eletrodos é de extrema importância para o presente estudo.

Adunka et al. ${ }^{17}$, em 2004, avaliaram o trauma intracoclear em 33 ossos temporais após a inserção do feixe de eletrodos por vias diferentes. Em 25 ossos a inserção foi via pequena cocleostomia anteroinferior à JR, e em oito ossos, a inserção foi via JR. O trauma foi observado em $48 \%$ dos ossos no primeiro grupo e quase $15 \%$ no segundo.

Briggs et al. ${ }^{43}$, em 2005, fizeram uma revisão de estudos em ossos temporais, com especial atenção sobre a relação anatômica da membrana da JR com a membrana basilar e o ligamento espiral, a fim de descrever a melhor localização para a realização da cocleostomia. Os autores concluíram que a cocleostomia deve ser realizada inferior a JR, ao invés de anterior, como era recomendado, para diminuir o trauma intracoclear e permitir a inserção do feixe de eletrodos na escala timpânica.

Adunka e Kiefer ${ }^{44}$, em 2006, avaliaram o trauma intracoclear em 21 ossos temporais divididos em 3 grupos: Grupo 1: Parada da inserção do feixe de eletrodos no primeiro ponto de resistência e feixe de eletrodos standard; Grupo 2: Parada da inserção do feixe de eletrodos no primeiro 
ponto de resistência e feixe de eletrodos flexível; e, Grupo 3: Inserção forçada nos pontos de resistência e feixe de eletrodos standard. A presença de trauma intracoclear grau 4, conforme a classificação de Eshraghi et al., nos grupos 1, 2 e 3 foi de $16,7 \%, 50 \%$ e $77,8 \%$, respectivamente. $\mathrm{Na}$ conclusão, os autores citaram que apesar dos feixes de eletrodos mais maleáveis permitirem inserções mais profundas, a flexibilidade destes eletrodos pode prejudicar a sensibilidade do cirurgião a resistências intracocleares.

Em 2006, Briggs et al. ${ }^{45}$, avaliaram , em 18 ossos temporais, o trauma intracoclear e a trajetória do feixe de eletrodos durante a inserção via JR ou via cocleostomia inferor a JR. Inserções completas sem resistências significativas foram obtidas em todas as peças. Não houve diferenças siginficativas entre os dois grupos.

Em 2007, Pau et al. ${ }^{20}$ mediram o nível de pressão sonora (SPL) ao qual a cóclea é exposta, durante a confecção da cocleostomia em quatro ossos temporais. Identificam valores superiores a $100 \mathrm{~dB}$ SPL no broqueamento de ossos próximos a cóclea, estes valores sobem para 107,2 dB SPL no broqueamento de uma fina camada óssea recobrindo a cóclea membranosa, podem chegar a $122 \mathrm{~dB}$ SPL quando o endósteo coclear é exposto, e, por fim, valores até $134 \mathrm{~dB}$ SPL foram alcançados quando a broca encostou no endósteo da cóclea.

Roland et al. ${ }^{46}$, em 2007 , apresentaram um estudo sobre a anatomia de ossos temporais de humanos. Descreveram que a escala timpânica tem trajeto descendente a partir da JR, e que para posicionar o feixe de 
eletrodos, paralelo à escala timpânica, o mesmo deve ser inserido de superoposterior para anteroinferior.

Meshik et al. ${ }^{47}$, em 2010, analisaram imagens tomográficas de oito ossos temporais, na tentativa de descrever o melhor vetor para inserção do feixe de eletrodos do IC na cóclea. Segundo as análises, o vetor que passa pelo centro da JR e tangente à linha central da escala timpânica representa o melhor vetor para que o feixe de eletrodos inserido via JR alcance a escala timpânica. No entanto, os autores supõem que durante a inserção, seguindo este vetor, o feixe de eletrodos precisa fazer uma curva abrupta ao redor da crista fenestra para alcançar a escala timpânica, portanto, não é factível efetuar este procedimento com os modelos de feixe de eletrodos disponíveis até o momento. Este estudo é teórico, pois os autores dependiam de análises computadorizadas de imagens de ossos temporais.

Outros estudos também compararam as diferentes localizações da cocleostomia.

Adunka et al. $^{48}$, em 2007, realizaram um estudo com 28 ossos temporais, a fim de comparar os traumas intracocleares relacionados à cocleostomias nas regiões anteroinferior ou inferior da JR. Os autores concluíram que cocleostomias na região inferior à JR causam menos traumas.

\subsection{Características anatômicas da janela redonda relevantes para inserção do feixe de eletrodos do implante coclear}

A anatomia da JR apresenta variações individuais. Segundo estudo 
anatômico realizado por Franz et al. $^{8}$, em 1987, no acesso à JR via timpanotomia posterior, o cirurgião visualiza parcialmente a metade anterior da membrana da JR, ficando a metade posterior recoberta pela projeção óssea posterior. No entanto, por causa de seu posicionamento horizontal, mesmo após o broqueamento desta projeção, a porção posterior não é bem visualizada. Além disso, os autores descreveram que a metade posterior da membrana é muito próxima à lâmina espiral óssea. A distância entre a lâmina espiral óssea e a membrana da JR é de $0,1 \mathrm{~mm}$ na região posterior. Esta distância aumenta em direção ao centro da membrana, e chega a aproximadamente $1 \mathrm{~mm}$. Em razão desta proximidade, o broqueamento da projeção posterior pode traumatizar a lâmina espiral óssea, mesmo que a membrana permaneça íntegra, em razão de sua elasticidade. Para completa visualização da metade anterior da membrana da JR também é necessário o broqueamento das projeções ósseas inferior e anteroinferior.

Em 2006, Roland e Wright ${ }^{49}$, realizaram uma revisão sobre estudos anatômicos. Apoiados na análise desses estudos, os autores descreveram que a metade posterior da membrana da JR é horizontalizada, está a menos de $1 \mathrm{~mm}$ de distância da lâmina espiral óssea, e que, não é necessária a sua visualização para a inserção do feixe de eletrodos na escala timpânica. Ao contrário, a metade anterior da membrana da JR é vertical e necessita de broqueamento mínimo para que possa ser visualizada.

Jiang e Fitzgerald ${ }^{50}$, em 2007, estudaram o acesso à JR via timpanotomia posterior em 50 pacientes. Em $72 \%$ dos casos $50 \%$ a $100 \%$ da membrana da JR pode ser visualizada após fácil remoção de projeções 
ósseas. Em $8 \%$ dos casos a membrana da JR não foi visualizada. Os autores acreditaram que esses casos estavam, provavelmente, associados a outras malformações do osso temporal. Concluíram que, na grande maioria dos pacientes, a membrana da JR pode ser adequadamente acessada.

Li et al. ${ }^{51}$, em 2007 , descreveram a proximidade da margem posterior da membrana da JR com a escala média, escala vestibular e ducto reuniens. As distâncias entre estas estruturas aumentam em direção à margem anteroinferior da membrana da JR.

Roland et. al. ${ }^{46}$, em 2007, em um estudo com 15 ossos temporais, estimaram que a área da JR coberta pela porção vertical de membrana varia de $0,8 \mathrm{~mm}^{2}$ a $1,75 \mathrm{~mm}^{2}$, com média de $1,39 \mathrm{~mm}^{2}$. Os autores afirmaram que broqueamentos de projeções ósseas do nicho da JR aumentam a área visível da membrana da JR, em média, de 1,5 a 3 vezes, podendo chegar até 13 vezes em nichos muitos estreitos. Estas dimensões da JR estão em concordância com trabalhos mais recentes ${ }^{52}$. 
4 MÉTODOS 


\section{MÉTODOS}

\subsection{Aspectos éticos da pesquisa}

O presente estudo foi aprovado pelo Comitê de Ética em Pesquisa da Faculdade de Medicina da Universidade de São Paulo (FMUSP), em 15.09.2010, como protocolo de pesquisa $n^{0} 262 / 10$, intitulado: "Estudo do trauma intracoclear pela inserção do feixe de eletrodos de implante coclear na janela redonda de ossos temporais" (Apêndice 1). Posteriormente, em 23.03.2012, a mesma Comissão aprovou adendo do protocolo informando que o projeto, acima intitulado, será realizado com peças de cadáver (Apêndice 2). O projeto de pesquisa também foi aprovado no Departamento de Radiologia da FMUSP em 21.11.2012 (Apêndice 3).

A pesquisa foi financiada pelas instituições de fomento: Fundação de Amparo à Pesquisa do Estado de São Paulo (FAPESP), processo $n^{0}$ 2011/20095-0, e Conselho Nacional de Desenvolvimento Científico e Tecnológico (CNPq), processo n ${ }^{0}$ 141656/2010-7.

\subsection{Material}

Foram utilizados 25 ossos temporais de cadáveres humanos, provenientes do serviço de verificação de óbitos (SVO) da Capital, São 
Paulo, retirados no período de até 24 horas após o óbito. Os ossos temporais foram excisados por um técnico do SVO.

Foram excluídos ossos temporais que apresentavam alterações macroscópicas na orelha externa e média, visualizadas durante a dissecção e ossos em que as estruturas do meato acústico interno não estavam preservadas. A causa mortis, gênero, idade, etnia e biótipo do cadáver não foram considerados critérios de exclusão do estudo.

\subsection{Aleatorização}

Para não haver discrepância entre os grupos, em relação à lateralidade das orelhas, as peças foram primeiramente divididas em blocos de orelhas direitas e esquerdas. Depois, as peças dos blocos foram aleatoriamente direcionadas, antes do congelamento, para grupo 1, no qual a inserção do feixe de eletrodos foi realizada pelo quadrante anterossuperior da JR, ou grupo 2, no qual a inserção do feixe de eletrodos foi realizada pelo quadrante anteroinferior da JR.

A aleatorização das peças foi gerada por meio de programa oferecido no endereço eletrônico Web Site Randomization (http://www.randomization.com) (Figura 1) 


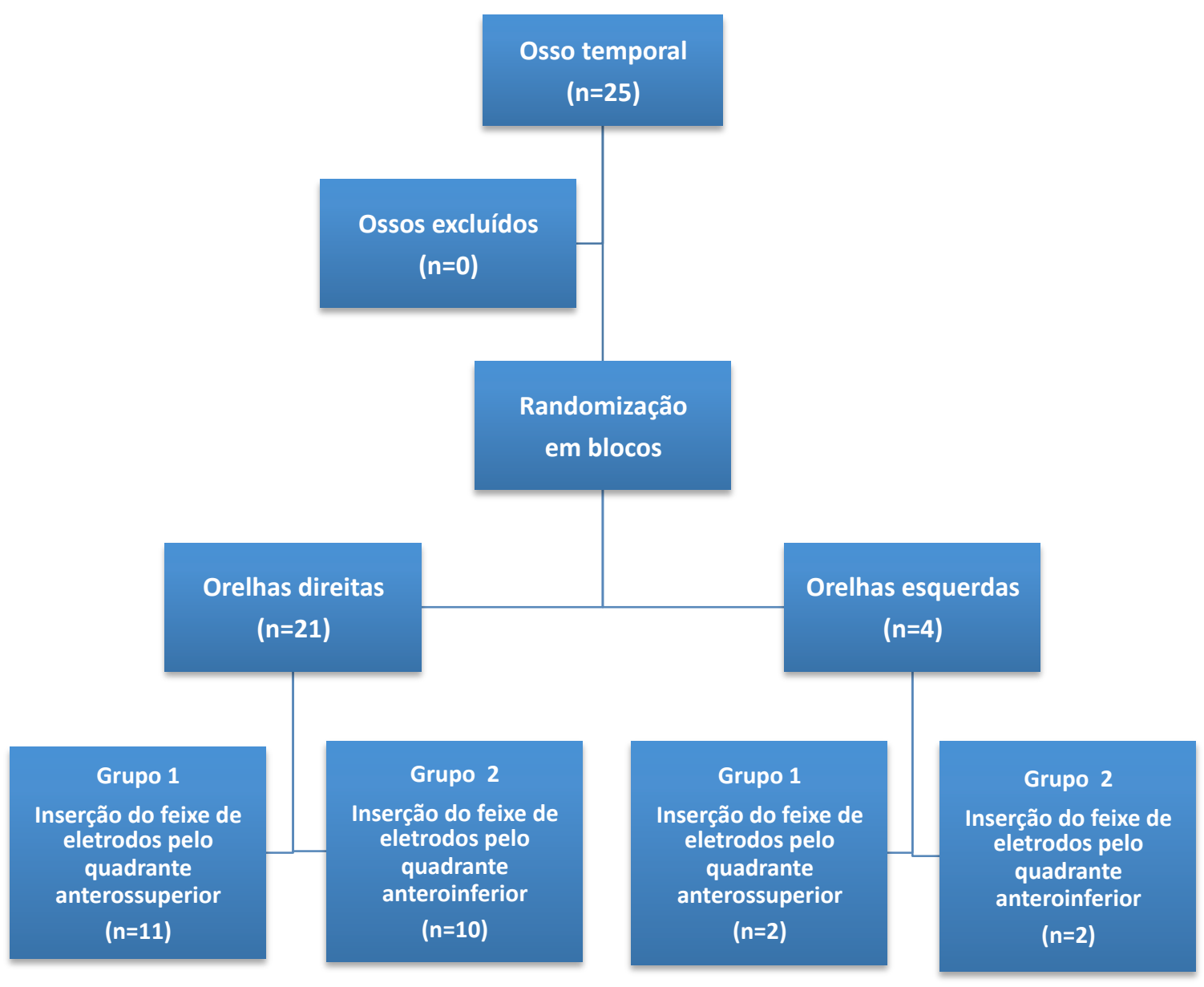

Figura 1 - Fluxograma de estudo dos ossos temporais

\subsection{Preparo dos ossos temporais para inserção do feixe de eletrodos do implante coclear}

Os ossos foram congelados e armazenados, a aproximadamente $-20^{\circ} \mathrm{C}$, no congelador do Laboratório de Habilidades Cirúrgicas em Otorrinolaringologia, chefiado pelo Prof. Dr. Rubens Vuono de Brito Neto, localizado na FMUSP. 
No dia da dissecção os ossos foram descongelados em temperatura ambiente (Figura 2).

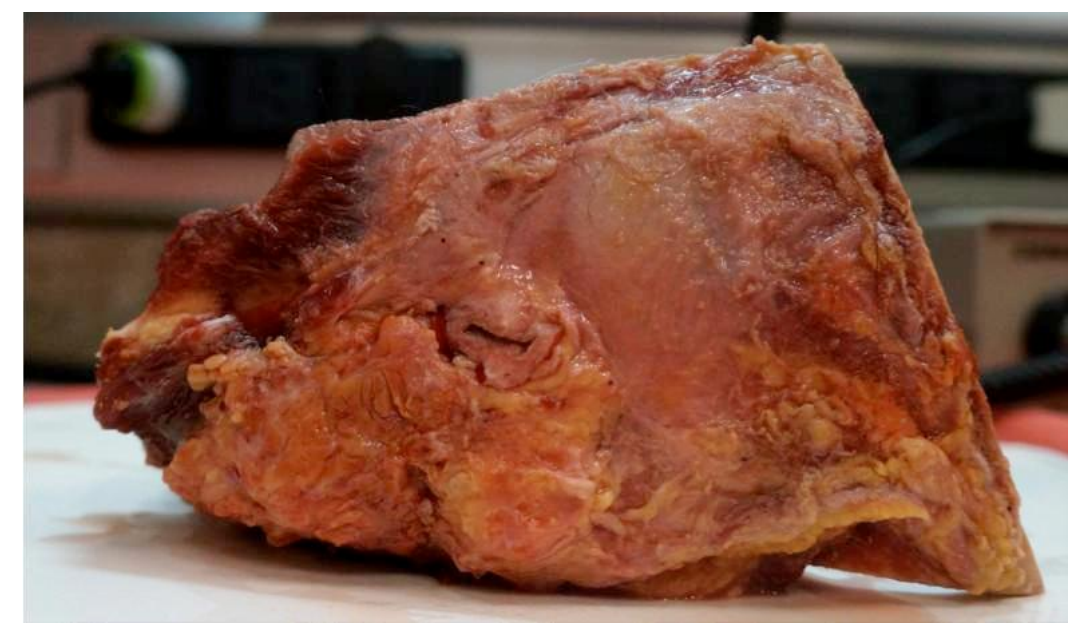

Figura 2 - Osso temporal após descongelamento até a temperatura ambiente

Estruturas anexas ao osso temporal que não interferiram no procedimento cirúrgico, como músculos e vasos, foram removidas (Figura 3).

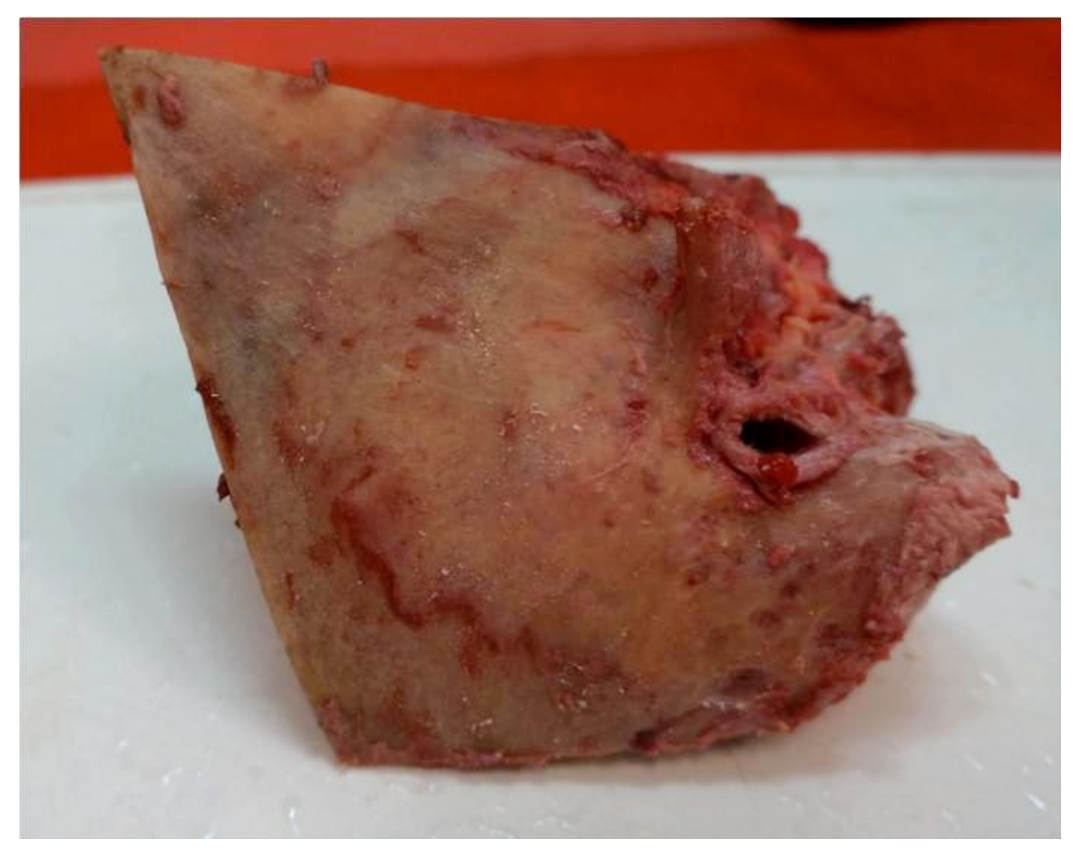

Figura 3 - Osso temporal após remoção de estruturas anexas 
Fixou-se os ossos descongelados em posição cirúrgica e, sob visão microscópica, realizou-se timpanomastoidectomia padrão (Figura 4). Isto inclui: identificação dos limites da orelha média, exposição do processo curto da bigorna e timpanotomia posterior ampla (Figura 5).

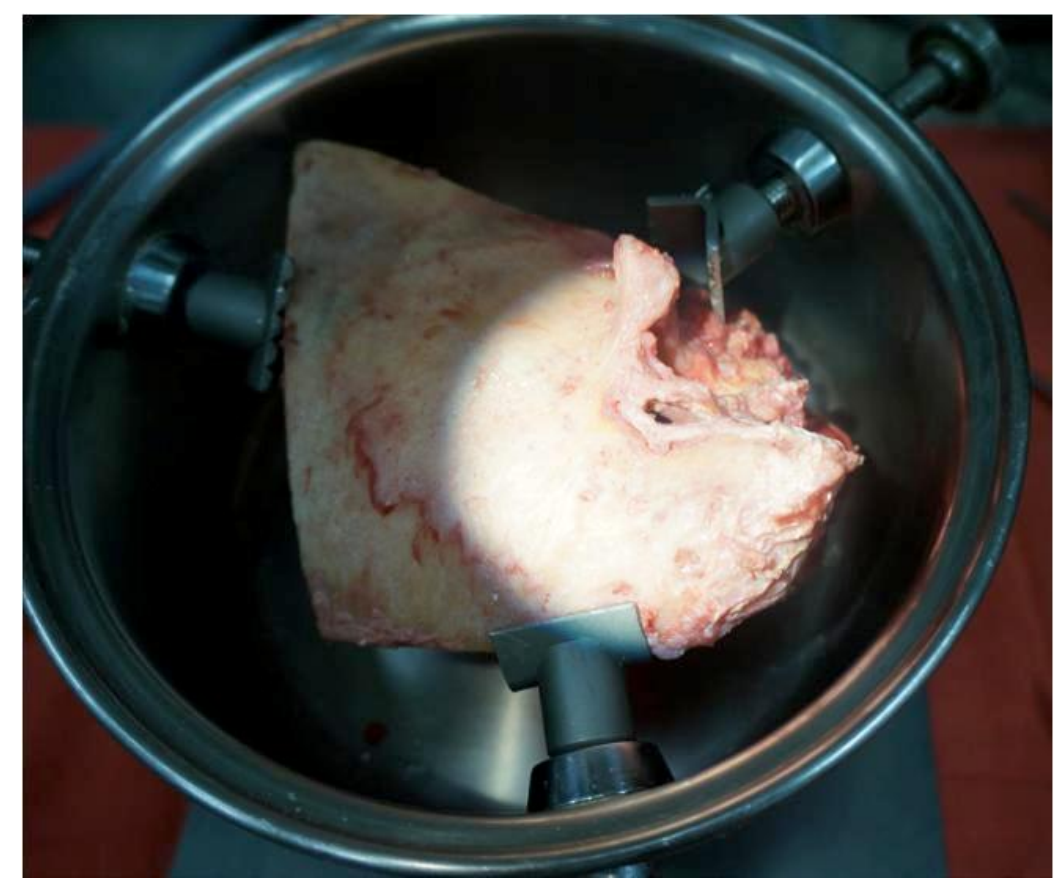

Figura 4 - Osso temporal fixado em posição cirúrgica, sob iluminação do microscópio

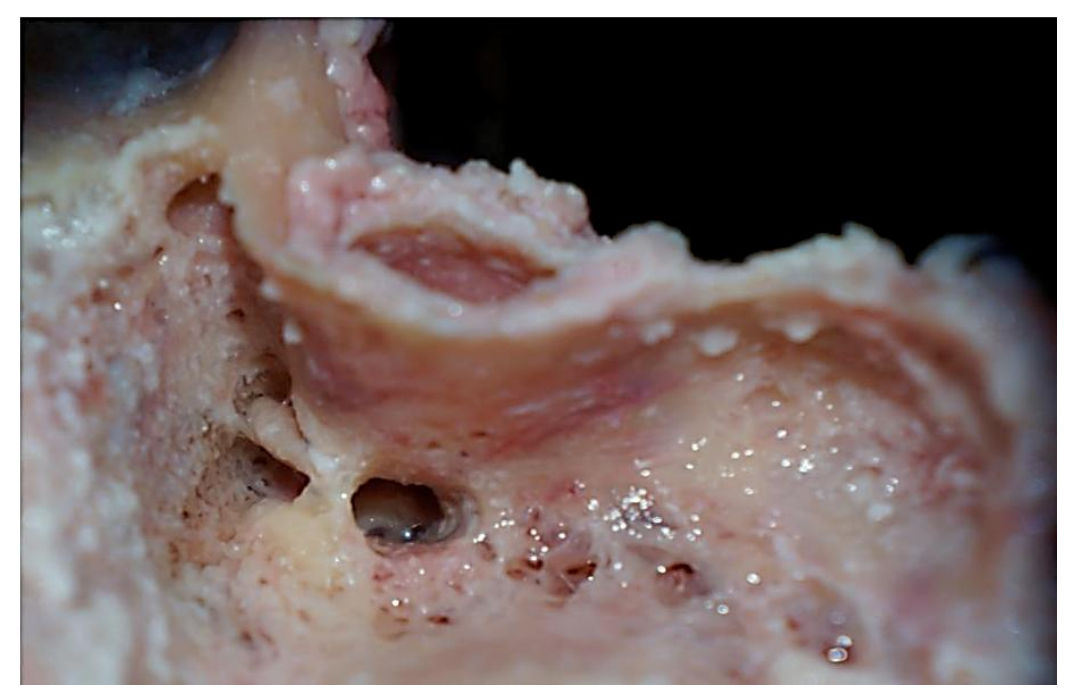

Figura 5 - Timpanomastoidectomia com timpanotomia posterior ampla 
Após identificação do nicho da JR, falsas membranas ou dobras de mucosas, quando presentes, foram removidas para exposição da membrana da JR (Figura 6).

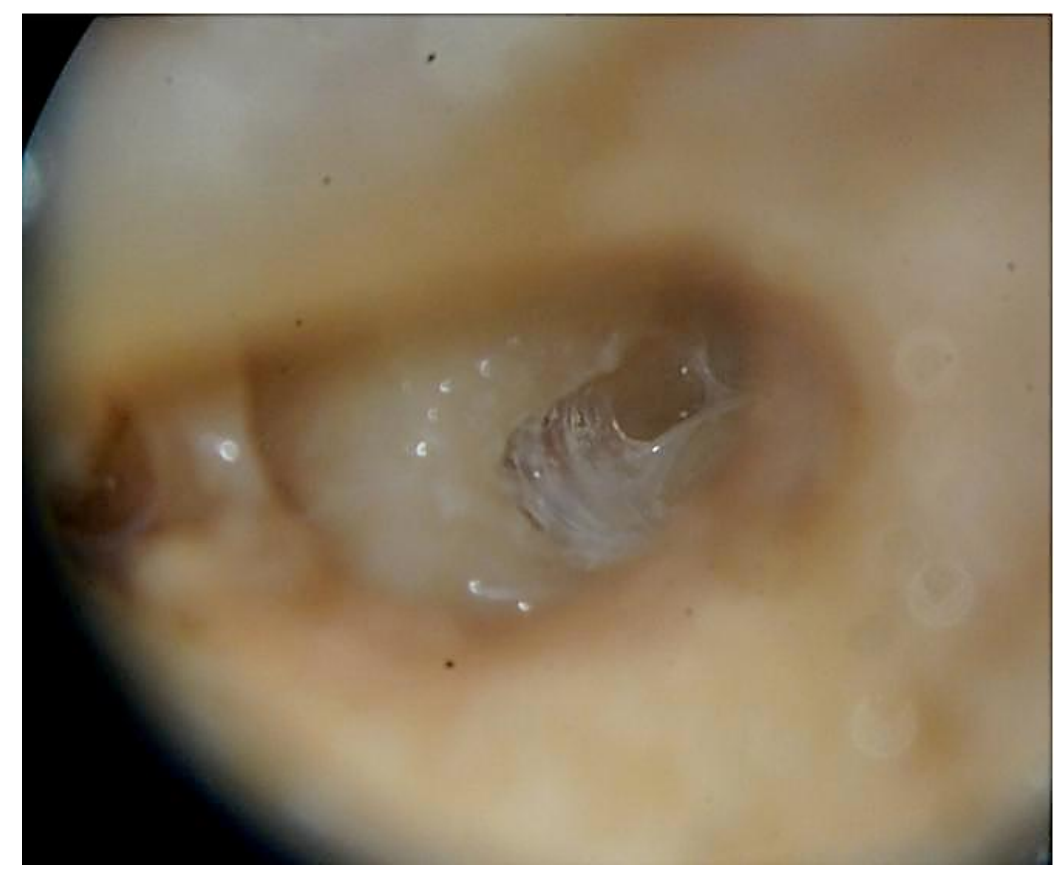

Figura 6 - Visualização, através da timpanotomia posterior, do nicho da janela redonda com identificação de falsa membrana

Projeções ósseas que dificultavam a visualização da membrana da JR foram brocadas com uma pequena broca diamantada, mantendo a membrana intacta (Figura 7 e 8 ). 


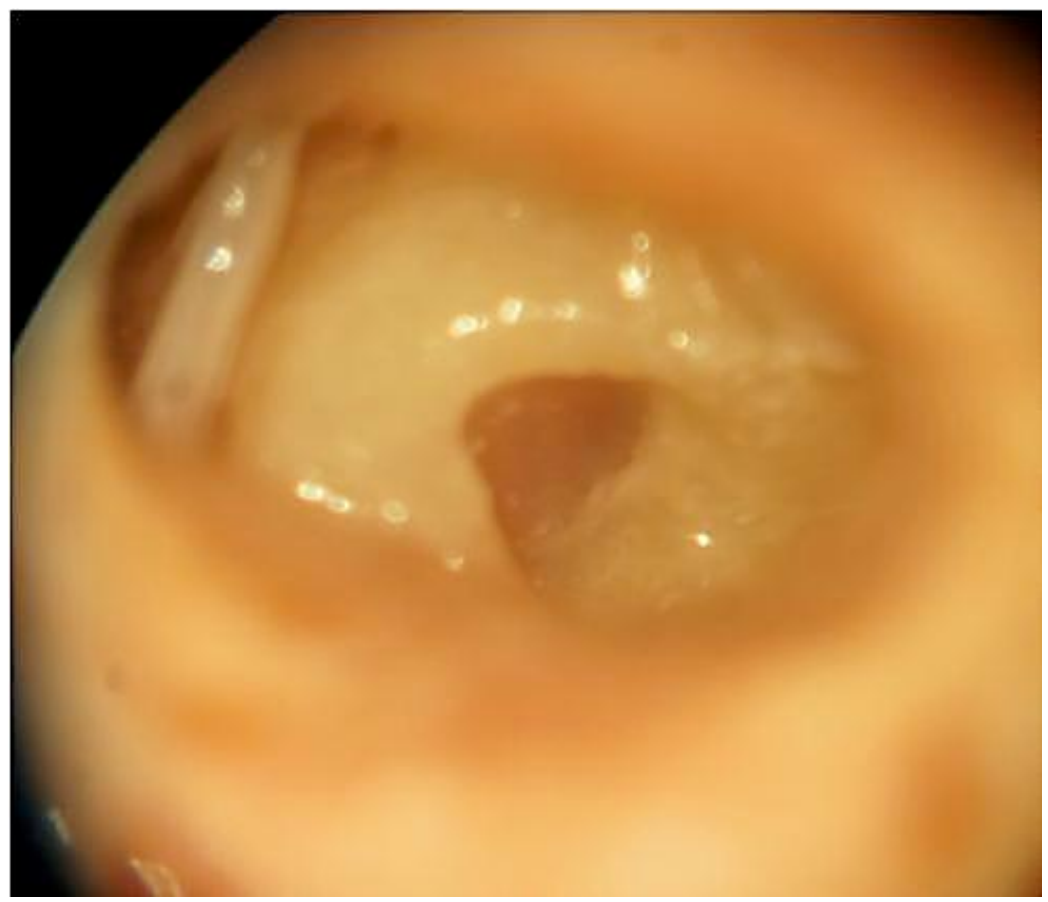

Figura 7 - Visualização, através da timpanotomia posterior, da membrana da janela redonda parcialmente recoberta por projeções ósseas

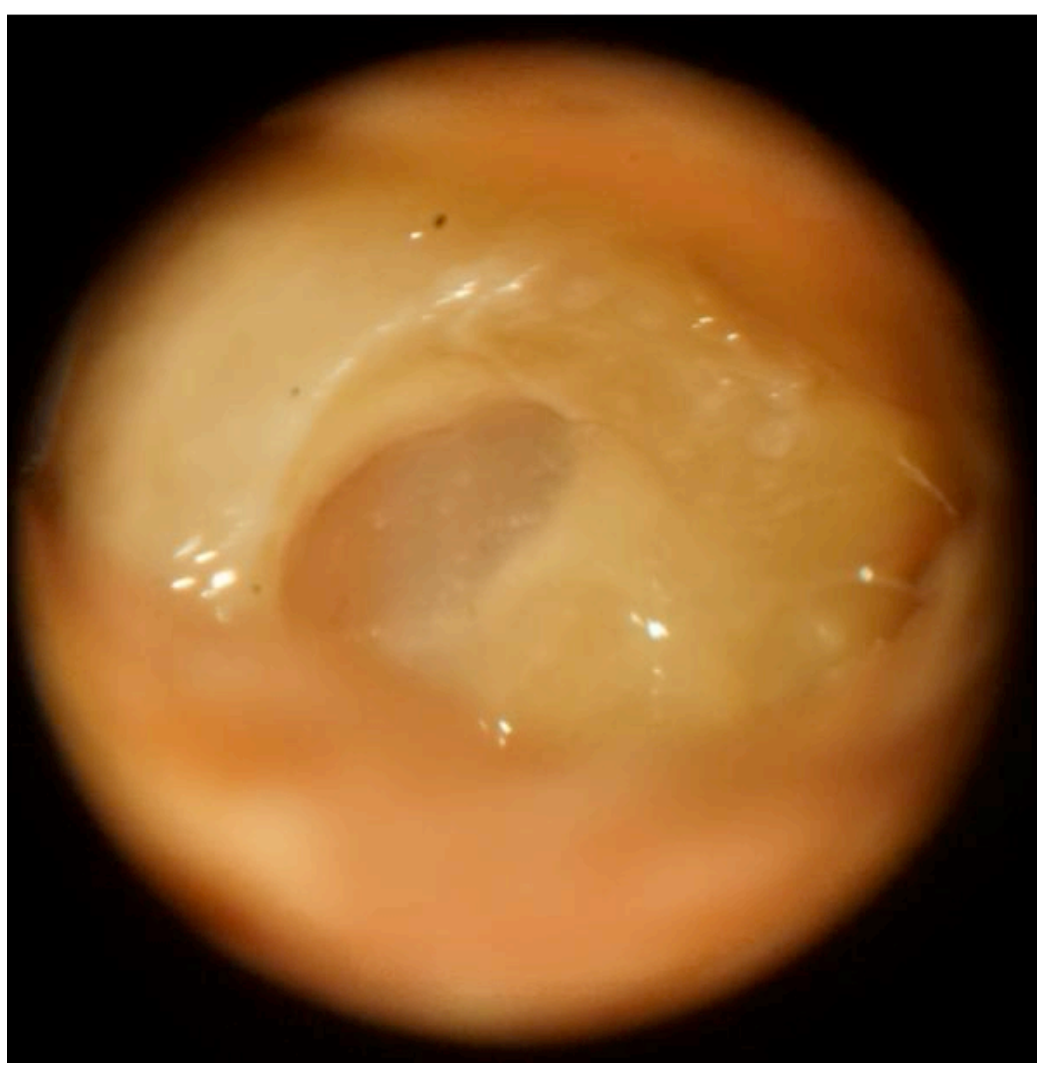

Figura 8 - Visualização, através da timpanotomia posterior, da membrana da janela redonda após remoção das projeções ósseas 
Conforme aleatorização, em 13 ossos a membrana da JR foi aberta no quadrante anterossuperior (Figura 9) e em 12 ossos no quadrante anteroinferior.As inserções dos feixes de eletrodos foram realizadas através destas aberturas (Figura 10). O mesmo cirurgião realizou todas as inserções.

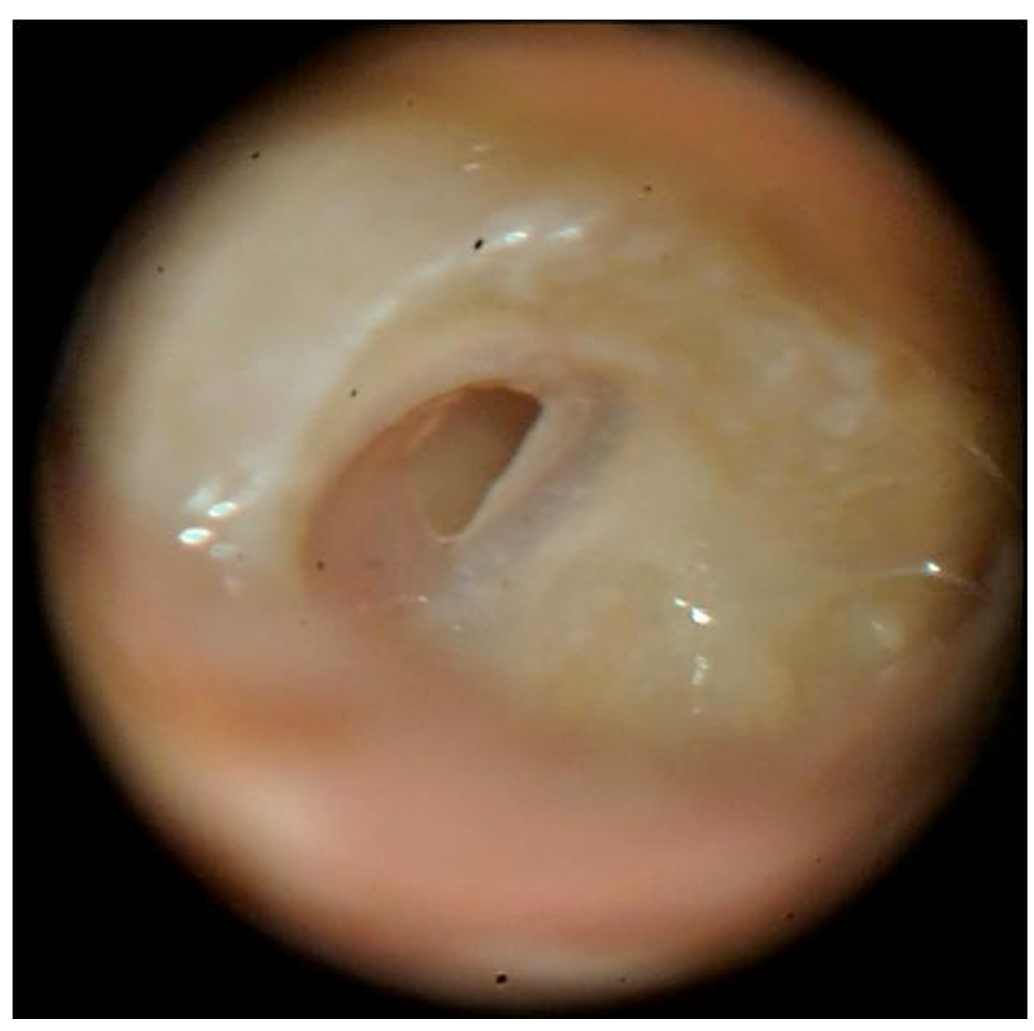

Figura 9 - Abertura no quadrante anterossuperior da membrana da janela redonda 


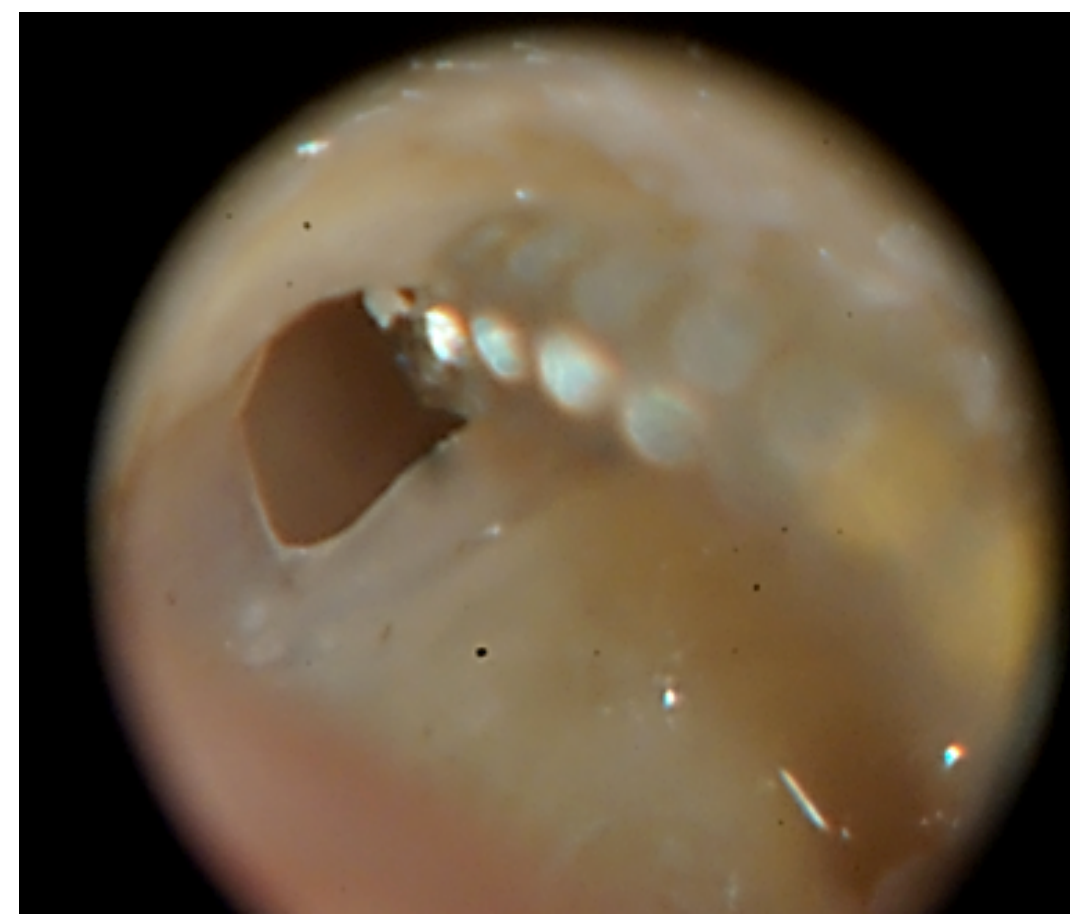

Figura 10 - Inserção do feixe de eletrodos através da abertura no quadrante anterossuperior da membrana da janela redonda

As platinas foram removidas para permitir o fluxo das substâncias, utilizadas no preparo histológico, por toda a cóclea. O feixe de eletrodos foi fixado com cola de etilcianoacrilato (Super Bonder ${ }^{\circledR}$ ), na região da timpanotomia posterior, a fim de prevenir mobilização do feixe durante a preparação das peças. Com os eletrodos fixos, realizou-se broqueamento para redução do tamanho da peça, preservando as estruturas da cavidade timpânica e orelha interna. No final de cada procedimento o cirurgião preencheu uma ficha de protocolo (Anexo A). 


\subsection{Feixe de eletrodos}

Foi utilizado o feixe de eletrodos $E V O^{\circledR}$ (Neurelec, Vallauris, França/Oticon Medical, Gothenburg, Suécia) (Figura 11). As suas dimensões estão apresentadas na Tabela 2.

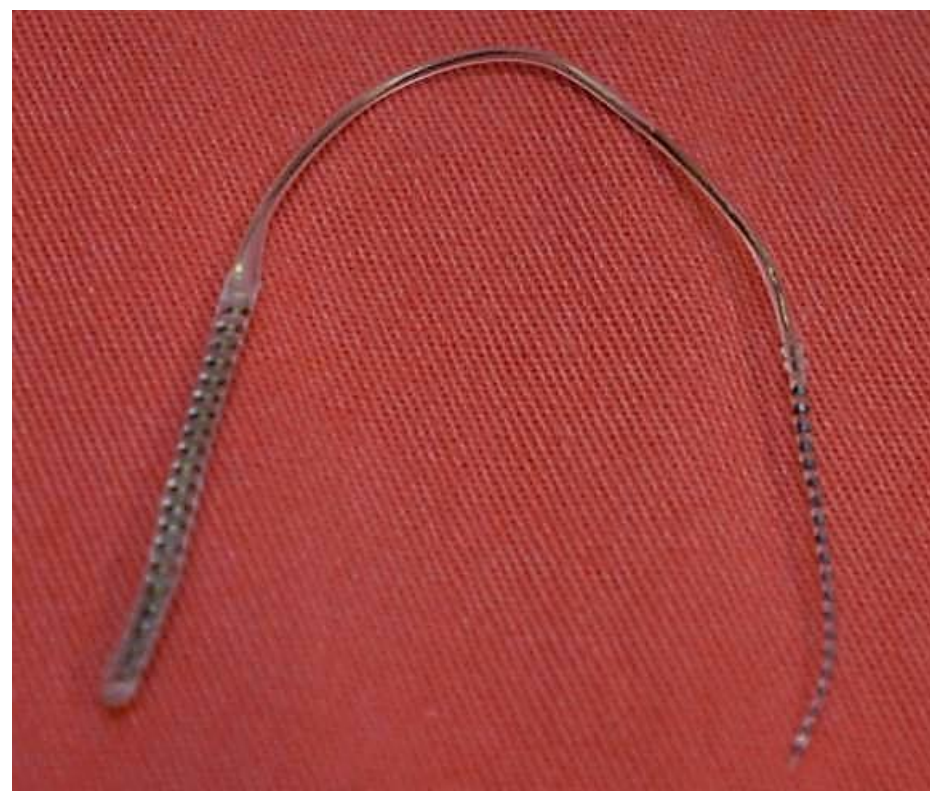

Figura 11 - Feixe de eletrodos EVO ${ }^{\circledR}$ (Neurelec, Vallauris, França/Oticon Medical, Gothenburg, Suécia)

Tabela 2 - Dimensões do feixe de eletrodos EVO ${ }^{\circledR}$ (Neurelec, Vallauris, França/Oticon Medical, Gothenburg, Suécia)

\begin{tabular}{lc}
\hline \hline Tipo de eletrodo & reto \\
Quantidade de eletrodos por feixe & 20 \\
Comprimento do feixe de eletrodos & $24 \mathrm{~mm}$ \\
Diâmetro proximal & $0,5 \mathrm{~mm}$ \\
Diâmetro médio & $0,45 \mathrm{~mm}$ \\
Diâmetro distal & $0,4 \mathrm{~mm}$ \\
Superfície do feixe & lisa \\
\hline \hline
\end{tabular}

FONTE: Nguyen et al., $2012^{53}$ 


\subsection{Preparo dos ossos temporais para análise histológica}

Após a inserção do feixe de eletrodos, os ossos foram imediatamente fixados em formaldeído a $10 \%$ por 24 horas. Após fixados, os ossos foram submetidos a concentrações crescentes de etanol e acetona, para remoção de toda a umidade, da forma seguinte:

○ Etanol a 70\% por 24 horas, com troca da solução a cada 12 horas;

- Etanol a 85\% por 24 horas, com troca da solução a cada 12 horas;

○ Etanol a 95\% por 24 horas, com troca da solução a cada 12 horas;

○ Etanol a $100 \%$ por 24 horas, com troca da solução a cada 12 horas;

o Acetona a 100\% por 24 horas, com troca da solução a cada 12 horas.

A agitação constante durante a desidratação aumenta a eficácia do processo. Para este fim, foi utilizada mesa agitadora orbital Orbital Shake ${ }^{\circledR}$ (Logen Scientific, Brasil) (Figura 12). 


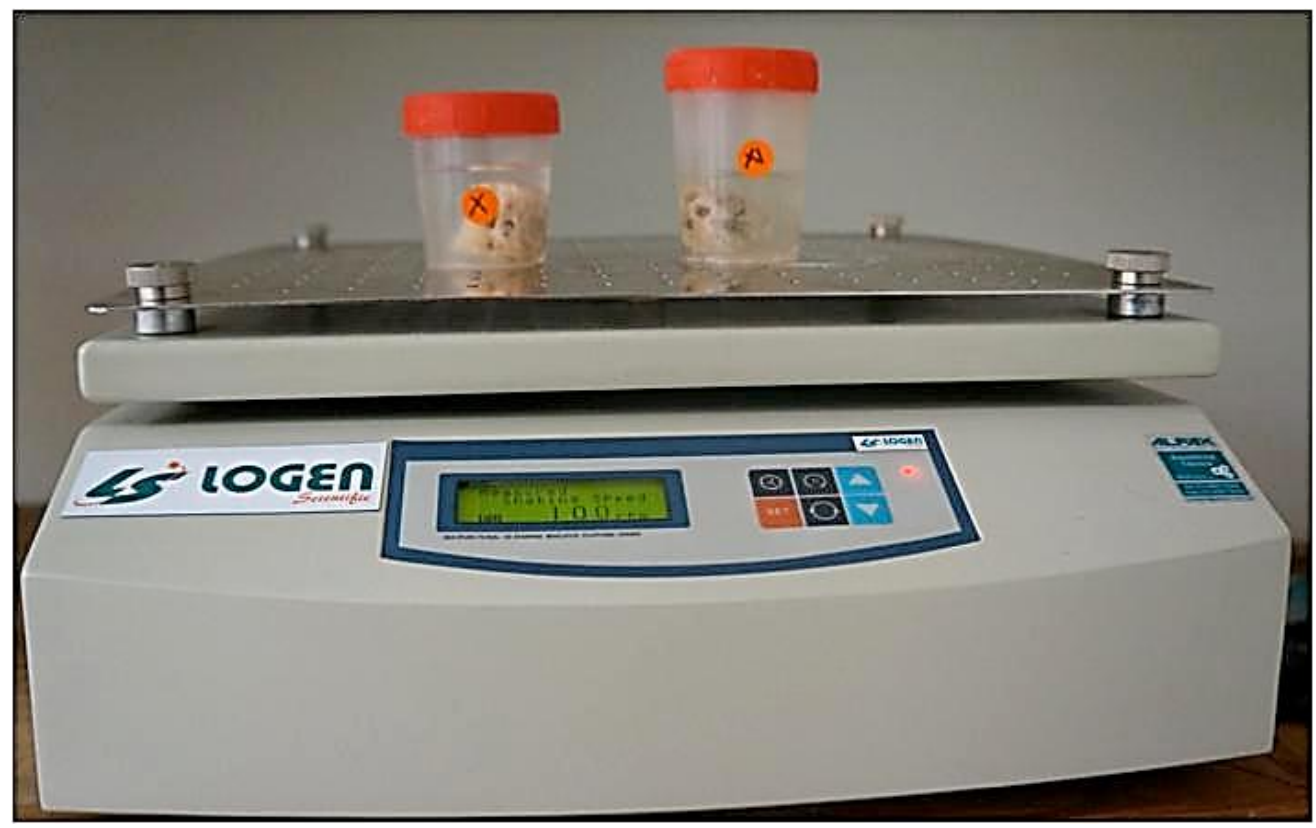

Figura 12 - Recipientes com ossos temporais imersos em etanol sobre a mesa agitadora Orbital Shake ${ }^{\circledR}$ (Logen Scientific, Brasil)

A secagem dos ossos após a remoção da acetona foi realizada em temperatura ambiente por aproximadamente 1 hora.

Os ossos desidratados foram embebidos em resina epóxi Epofix ${ }^{\circledR}$ (Struers, Ballerup, Dinamarca), colocados em dessecador, e submetidos ao ambiente com vácuo, com auxílio da bomba Vacuubrand PC3001 Basic $^{\circledR}$ (Vacuubrand, Wertheim, Alemanha), para promover a penetração da resina por toda a cóclea e remoção de bolhas de ar (Figura 13). 


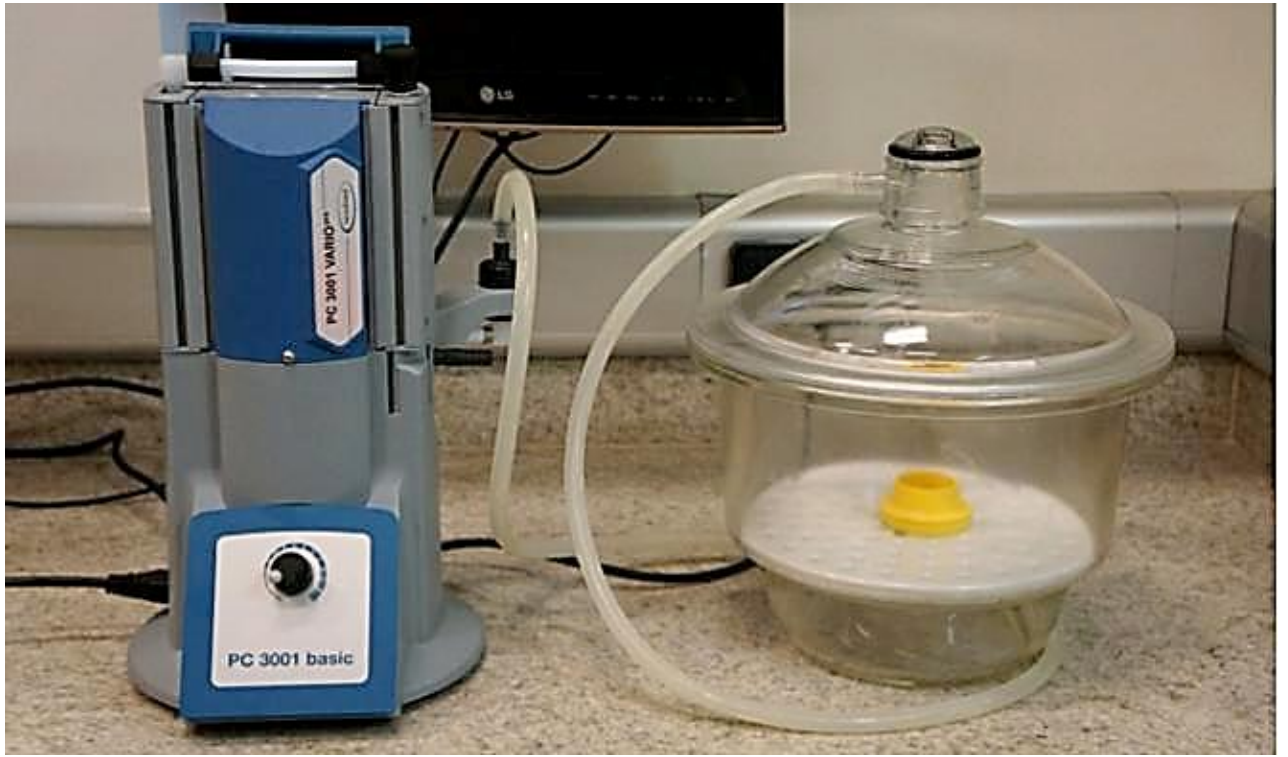

Figura 13 - Osso temporal imerso em resina epóxi, dentro do dessecador submetido a vácuo (Bomba Vacuubrand PC3001 basic ${ }^{\circledR}$ Vacuubrand, Wertheim, Alemanha)

Após 10 minutos, a bomba foi desligada, o dessecador aberto, as peças voltaram a ficar em pressão ambiente e permaneceram em temperatura ambiente por 24 horas para endurecimento da resina (Figura 14).

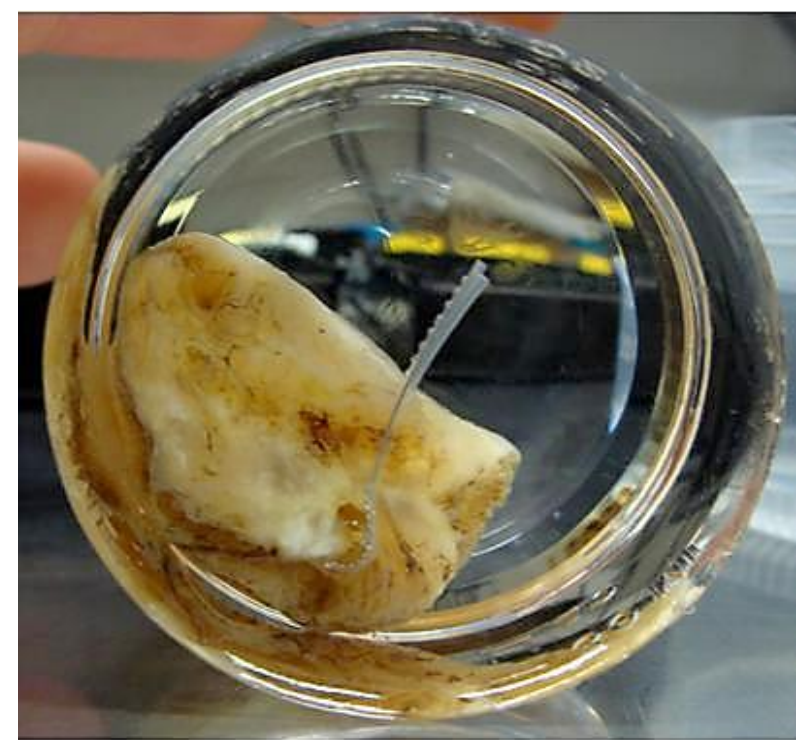

Figura 14 - Osso temporal embutido em resina epóxi (Resina Epofix ${ }^{\circledR}$ - Struers, Ballerup, Dinamarca) 
Em seguida, os ossos foram submetidos à tomografia computadorizada (TC) em tomógrafo Discovery CT 750 HD ${ }^{\circledR}$ (General Eletric, Fairfield, EUA), localizado no Instituto Central do Hospital das Clínicas da FMUSP (HC-FMUSP) (Figura 15).

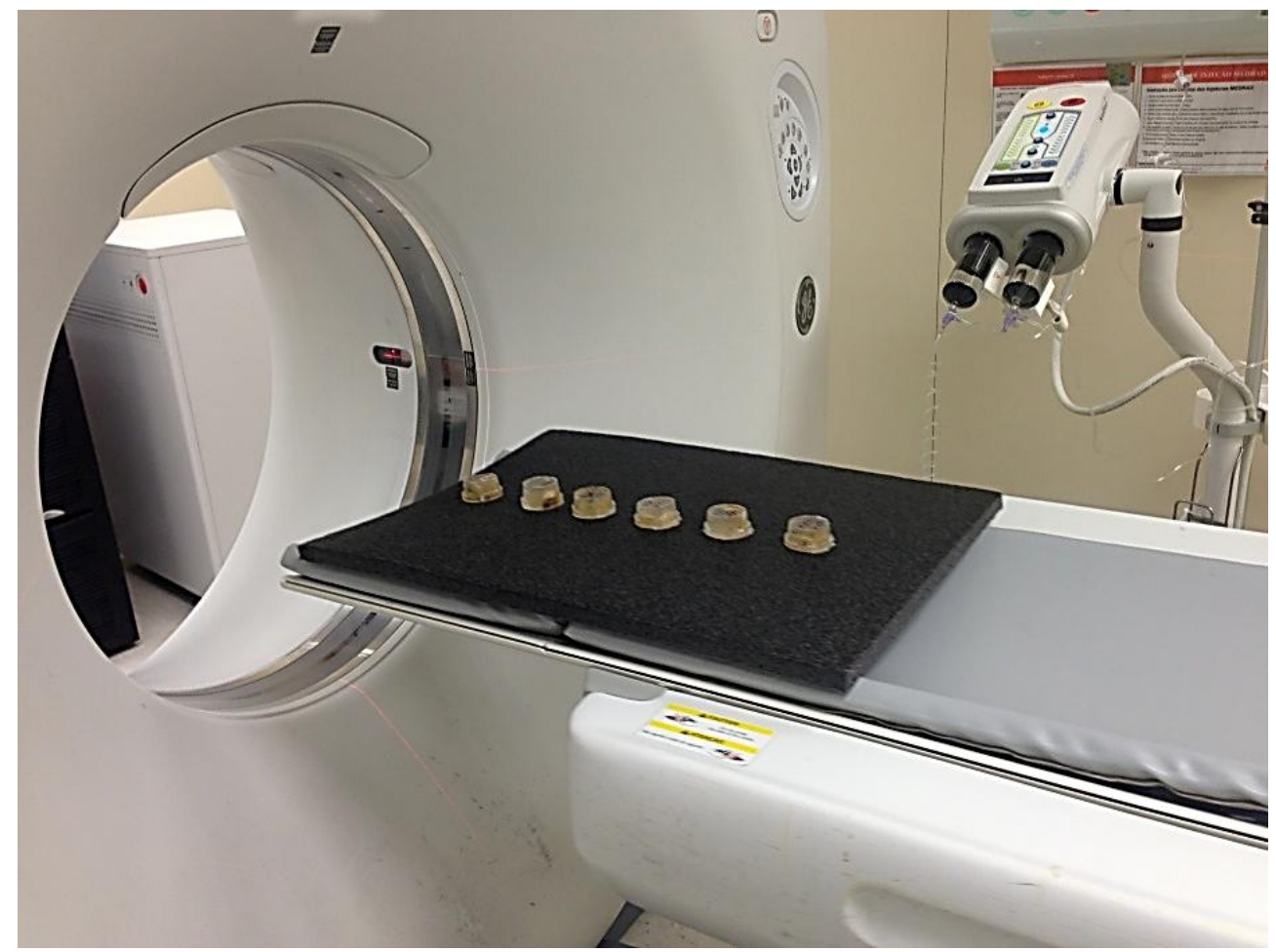

Figure 15 - Ossos temporais embutidos em resina epóxi, posicionados para ser realizada a tomografia computadorizada

Após a realização da $\mathrm{TC}$, os ossos foram polidos com auxílio de máquina polidora plana LaboPol- $5^{\circledR}$ (Struers, Ballerup, Dinamarca), com lixa de granulometria 800 , sob irrigação contínua de água (Figura 16). O plano do polimento foi paralelo à membrana da JR. 


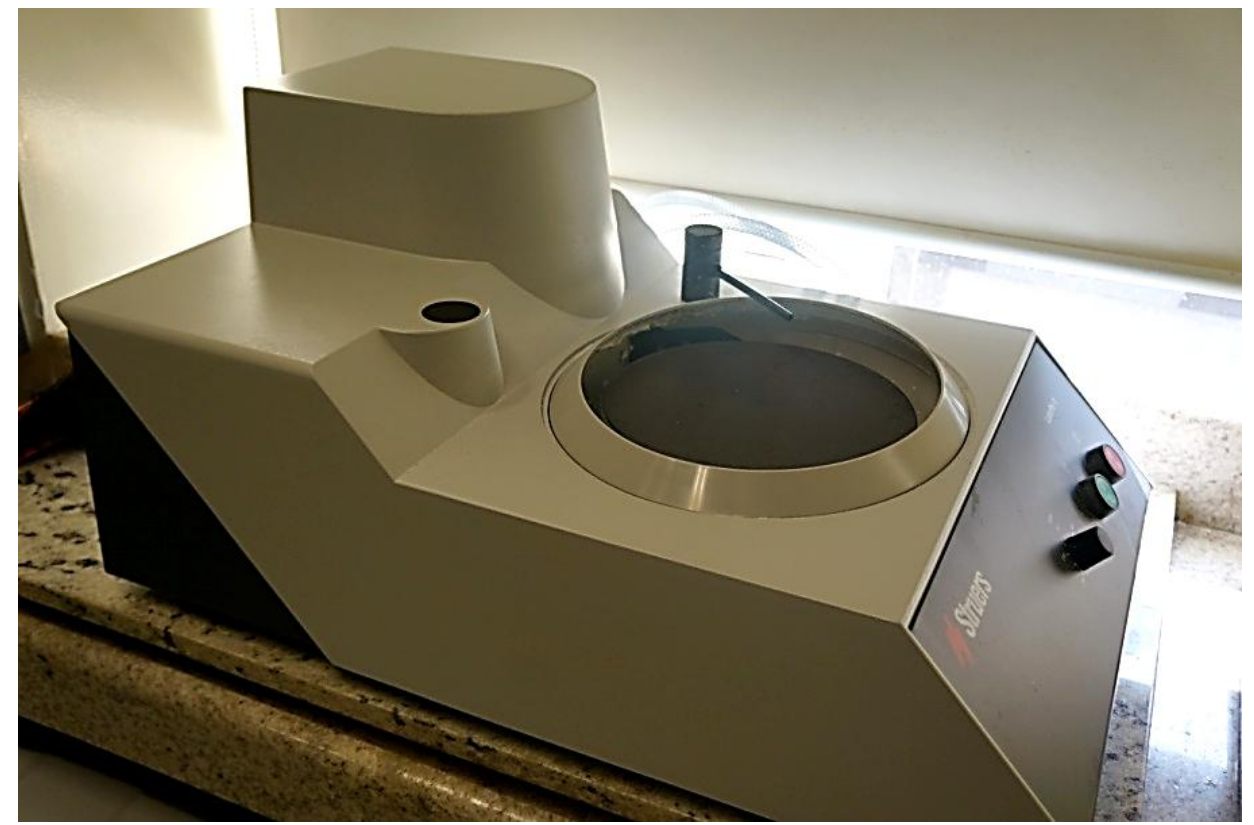

Figura 16 - Máquina polidora (LaboPol- $5^{\circledR}$ - Struers, Ballerup, Dinamarca)

Ao final de cada sessão de polimento, com profundidade de $500 \mu \mathrm{m}$, a superfície de osso embutido em epóxi, que ficou exposta, foi tingida com corante azul de toluidina $\mathrm{O}$ (Sigma-Aldrich, São Paulo, Brasil), por aproximadamente 45 minutos.

As superfícies tingidas foram visualizadas em estereomicroscópio Discovery $V 8^{\circledR}$ (Carl Zeiss, Göttingen, Alemanha), para avaliação das estruturas intracocleares. As imagens foram coletadas por meio da câmera digital científica AxionCam ERc $5 s^{\circledR}$ (Carl Zeiss, Göttingen, Alemanha) acoplada ao estereomicroscópio, e armazenadas em computador com programa AxionVision $^{\circledR}$ (Carl Zeiss, Göttingen, Alemanha) (Figura 17 e 18). Cada superfície polida foi fotografada com magnitudes de 15x, 30x, 60x, 94x e 120x. Após a coleta das imagens, os ossos foram novamente polidos para exposição de novas superfícies. O procedimento foi repetido a cada $500 \mu \mathrm{m}$ até a visualização de toda a cóclea. 


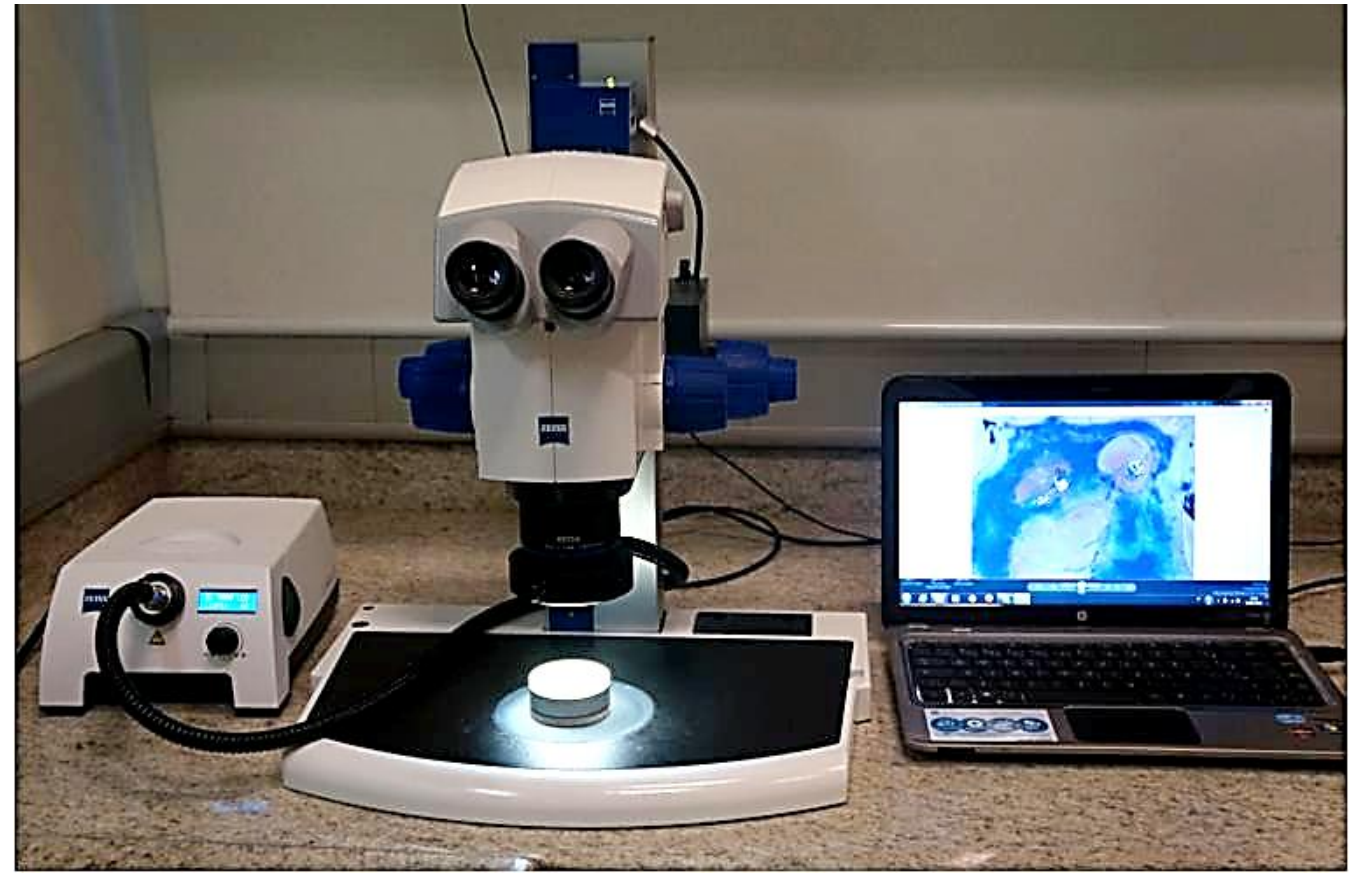

Figura 17 - Estereomicroscópio (Discovery V8 ${ }^{\circledR}$ - Carl Zeiss, Göttingen, Alemanha) acoplado à câmara digital (AxionCam ERc $5 s^{\circledR}$ - Carl Zeiss, Göttingen, Alemanha) e computador com programa AxionVision ${ }^{\circledR}$ (Carl Zeiss, Göttingen, Alemanha)

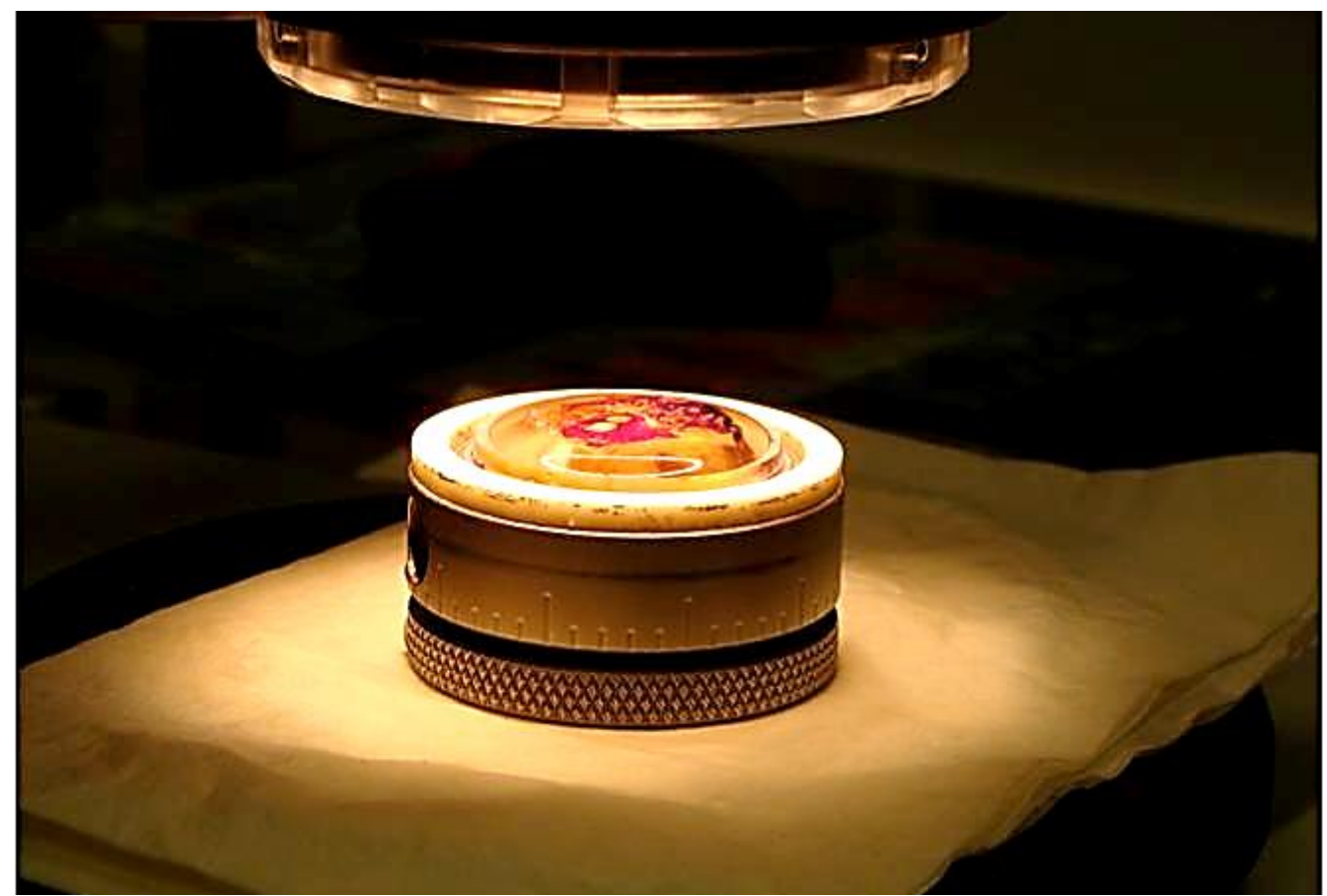

Figura 18 - Osso temporal sob iluminação do estereomicroscópio (Discovery V8 ${ }^{\circledR}$ Carl Zeiss, Göttingen, Alemanha) 
Durante a análise histológica, as cócleas foram divididas em cinco segmentos a fim de padronizar as áreas intracocleares (Figura 19).

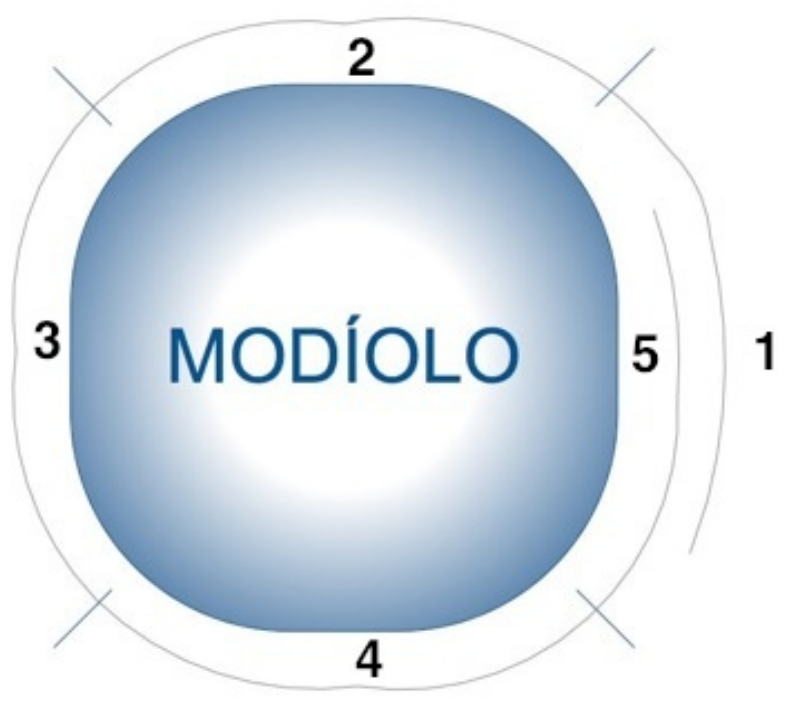

Figura 19 - Representação diagramática dos segmentos da cóclea

O início do segmento 1 é a membrana da JR, e o início dos segmentos 2 e 4 é definido a partir da primeira superfície em que não se visualiza o modíolo. Nestes últimos dois segmentos o eletrodo é visualizado na transversal.

$\mathrm{Na}$ análise histológica foi utilizada a classificação proposta por Eshraghi et al. ${ }^{30}$, apresentada na Tabela 1.

\subsection{Análise estatística}

A quantidade de ossos temporais disponíveis para pesquisa era 
limitada, por isso foi adotada amostra de conveniência com 25 ossos temporais.

Os dados obtidos no estudo foram digitados em uma planilha Microsoft Excel ${ }^{\circledR}$.

Nos dois grupos, a quantidade de superfícies expostas por peça, a presença de trauma intracoclear e o grau de trauma em cada segmento foram descritos com o uso de frequências absolutas e relativas.

Foi verificada existência de associação, entre a presença de trauma intracoclear e o quadrante de inserção do feixe de eletrodos, mediante teste exato de Fisher ${ }^{54}$.

Os graus de trauma em cada segmento foram comparados entre os dois grupos com a aplicação do teste Mann-Whitney ${ }^{54}$. Em todos os testes, o nível descritivo (valor de $p$ ) $\leq 0,05$ foi considerado estatisticamente significante.

Foram utilizados os programas estatísticos Stata 10.1 for MAC (StataCorp, Texas, EUA), e o Statistical Package for Social Science 20.0 for Windows (SPSS Inc., Chicago, EUA). 
5 RESULTADOS 


\section{RESULTADOS}

\subsection{Descrição dos ossos temporais}

Aplicando os critérios previamente expostos, foram incluídos 25 ossos temporais, excisados de cadáveres humanos, provenientes do SVO da Capital, retirados em até 24 horas após o óbito, no período de dezembro de 2012 a julho de 2013.

Nenhum osso temporal foi excluído. As características dos 25 ossos temporais, observadas durante as cirurgias, constam da Tabela 3.

Tabela 3 - Descrição das características dos ossos temporais do grupo 1 $(n=13)$ e grupo $2(n=12)$

\begin{tabular}{|c|c|c|}
\hline \multirow[b]{2}{*}{ Características } & \multicolumn{2}{|c|}{ Inserção pelo quadrante } \\
\hline & $\begin{array}{c}\text { anterossuperior } \\
\text { (grupo 1) } \\
\text { n (\%) }\end{array}$ & $\begin{array}{c}\text { anteroinferior } \\
\text { (grupo 2) } \\
\text { n (\%) }\end{array}$ \\
\hline $\begin{array}{l}\text { Lado } \\
\text { Direito } \\
\text { Esquerdo }\end{array}$ & $\begin{array}{c}11(84,6) \\
2(15,4)\end{array}$ & $\begin{array}{c}10(83,3) \\
2(16,7)\end{array}$ \\
\hline $\begin{array}{l}\text { Necessidade de } \\
\text { de projeções óss } \\
\text { da janela redond } \\
\text { Sim } \\
\text { Não }\end{array}$ & $\begin{array}{c}13(100,0) \\
0(0,0)\end{array}$ & $\begin{array}{c}12(100,0) \\
0(0,0)\end{array}$ \\
\hline $\begin{array}{l}\text { Presença de fals } \\
\text { da janela redond } \\
\text { Sim } \\
\text { Não }\end{array}$ & $\begin{array}{c}10(76,9) \\
3(23,1)\end{array}$ & $\begin{array}{l}9(75,0) \\
3(25,0)\end{array}$ \\
\hline $\begin{array}{l}\text { Tipo de inserção } \\
\text { Completa } \\
\text { Parcial } \\
\end{array}$ & $\begin{array}{c}13(100,0) \\
0(0,0) \\
\end{array}$ & $\begin{array}{c}12(100,0) \\
0(0,0)\end{array}$ \\
\hline
\end{tabular}


Em todas as peças foi necessário o broqueamento de projeções ósseas do nicho da JR, que limitavam a visibilidade e acessibilidade da membrana da JR.

Em 25 peças conseguiu-se inserção completa do feixe de eletrodos com nenhuma ou mínima resistência. Em um osso, após inserção completa, o feixe de eletrodos retrocedeu poucos milímetros.

\subsection{Análise das tomografias computadorizadas}

Todas as peças foram submetidas à TC.

O feixe de eletrodos foi visualizado em posição intracoclear em todos os ossos temporais (Figura 20).

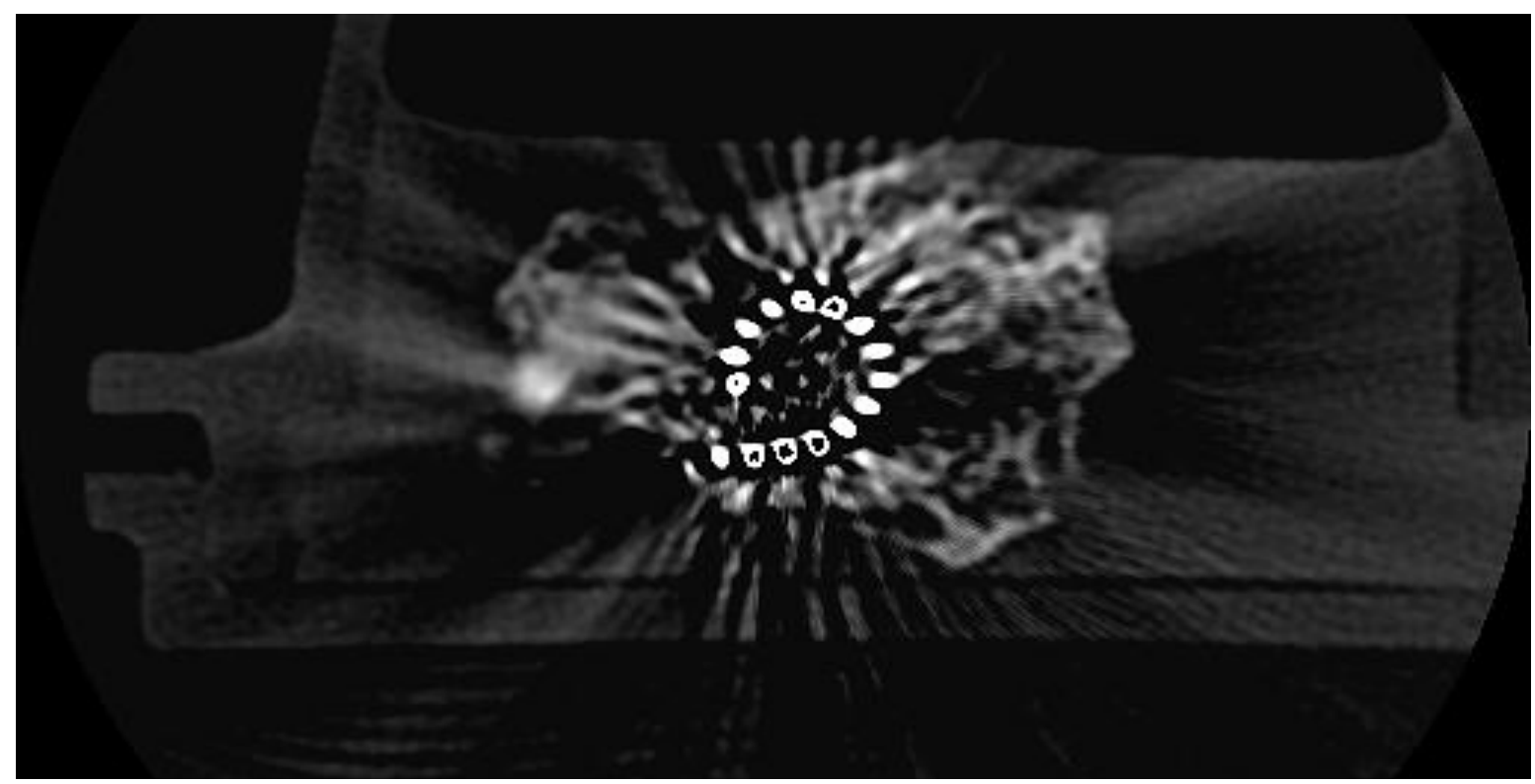

Figura 20 - Imagem de tomografia computadorizada com visualização do feixe de eletrodos intracoclear 


\subsection{Análises histológicas}

Foram analisadas todas as superfícies a partir da membrana da JR ate o final da cóclea. As Figuras 21 a 25 mostram exemplos dos diferentes segmentos.

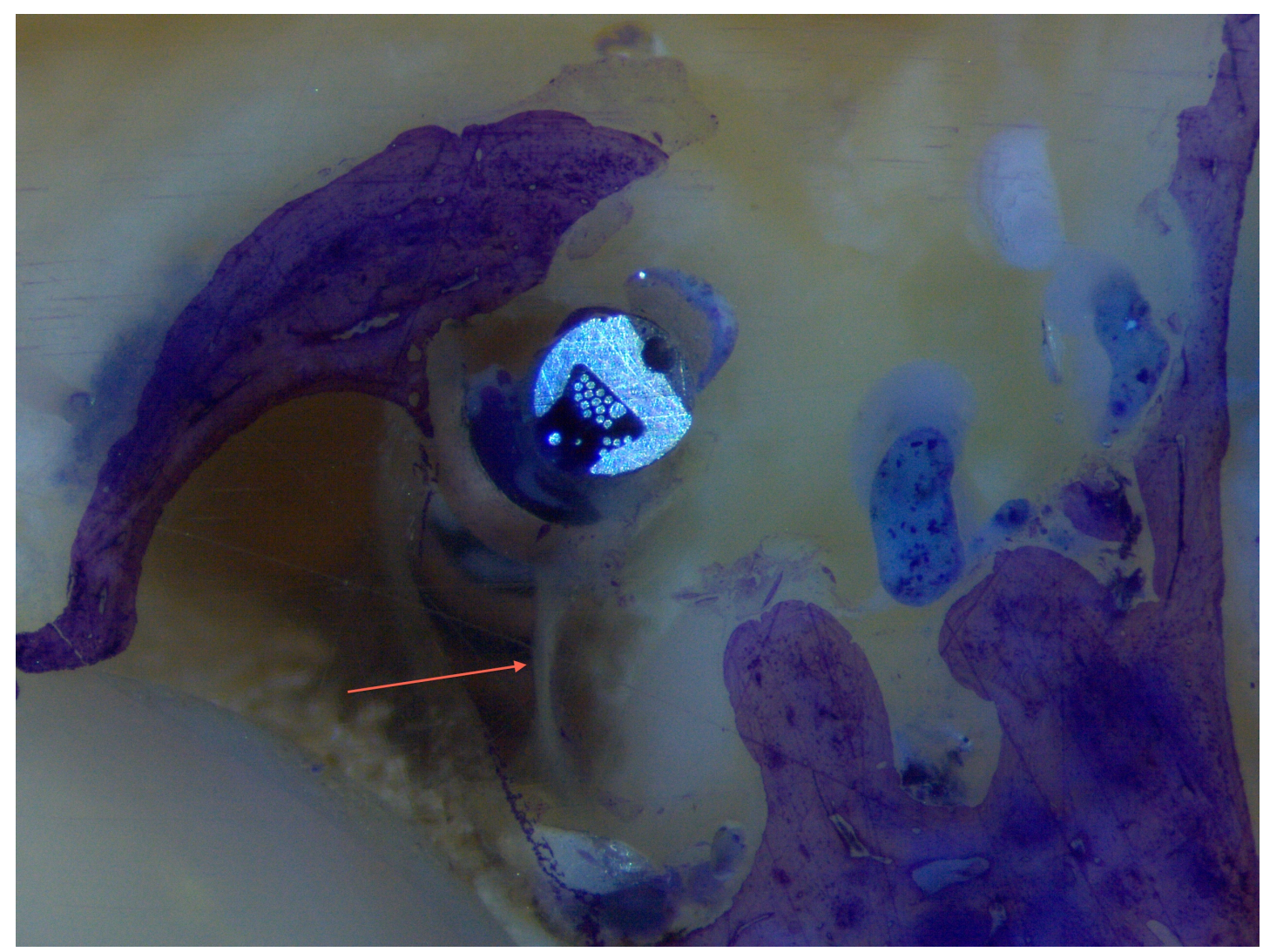

Figura 21 - Visualização da membrana da janela redonda (seta vermelha), determinando o limite inicial do segmento 1 (Estereomicroscópio Discovery V8 ${ }^{\circledR}$ - Carl Zeiss, Göttingen, Alemanha. Aumento de 30x. Coloração azul de toluidina O) 


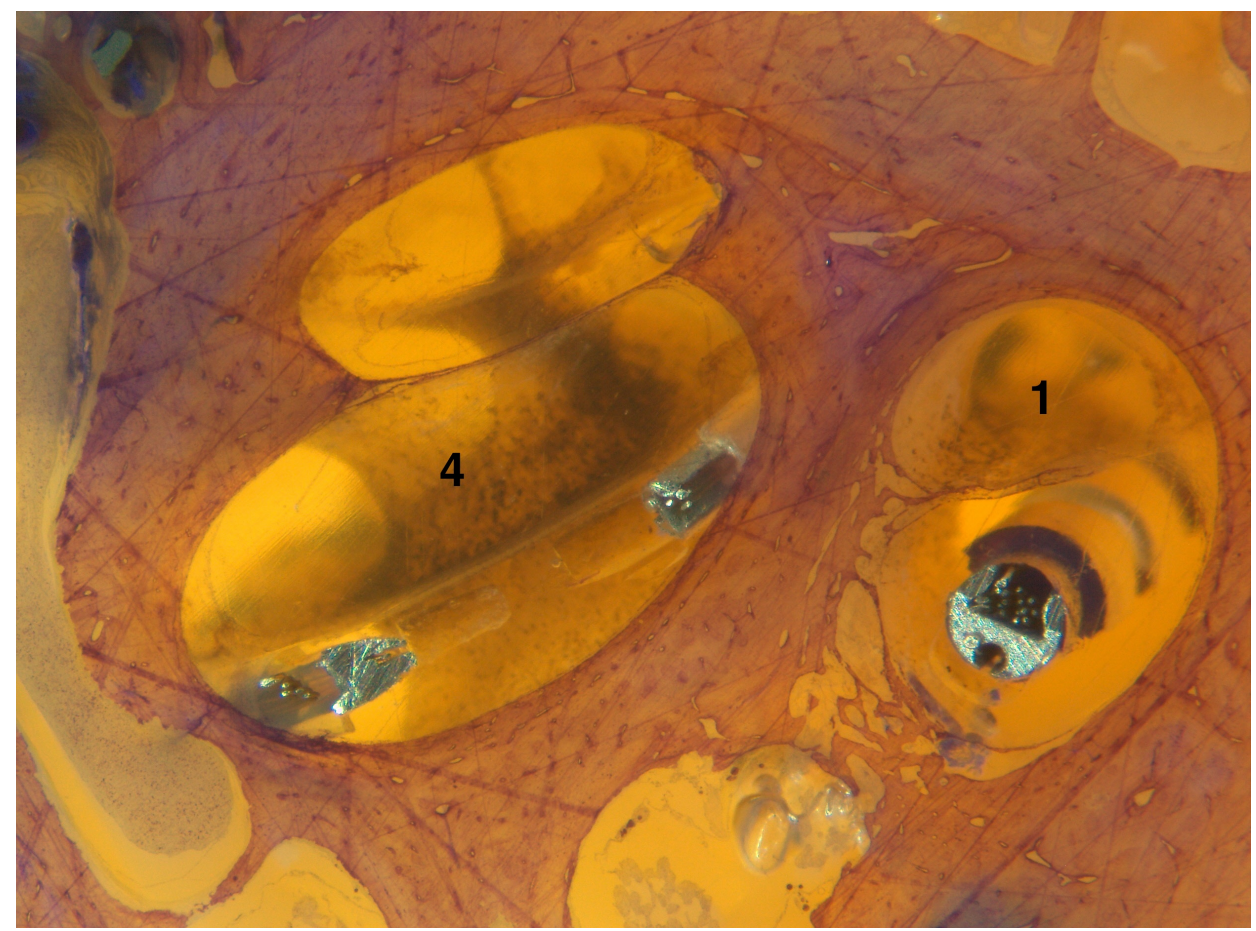

Figura 22 - Identificação dos segmentos 1 e 4 . Modíolo visualizado mais profundo à superfície da peça (Estereomicroscópio Discovery V8 ${ }^{\circledR}$ - Carl Zeiss, Göttingen, Alemanha. Aumento de 15x. Coloração azul de toluidina O)

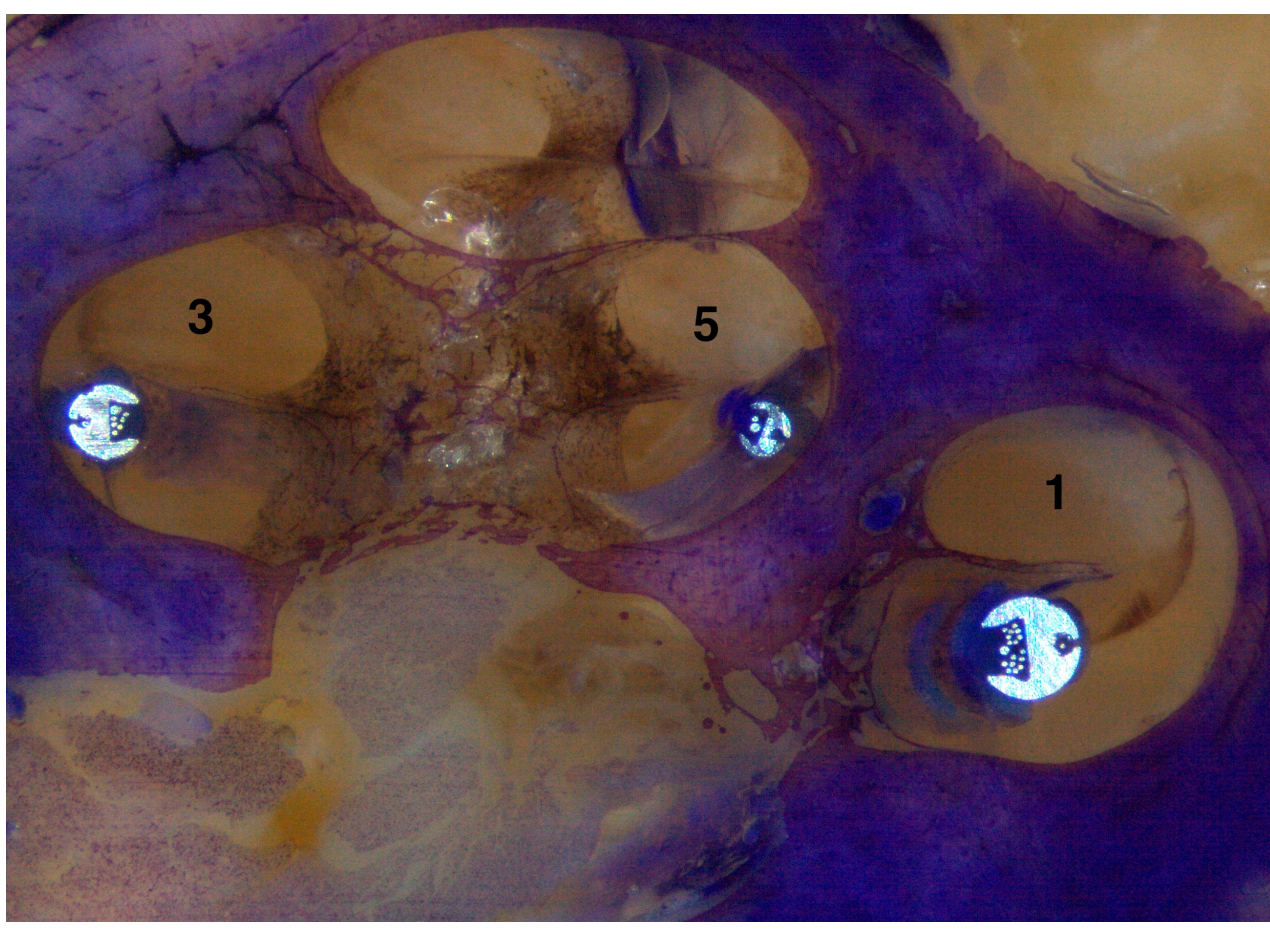

Figura 23 - Identificação dos segmentos 1, 3 e 5. Inicio da visualização do modíolo na superfície da peça, definindo início dos segmentos 3 e 5 (Estereomicroscópio Discovery $\mathrm{V}^{\circledR}$ - Carl Zeiss, Göttingen, Alemanha. Aumento de 15x. Coloração azul de toluidina O) 
As Figuras 24 e 25 são da mesma peça. A Figura 24 é a última superfície em que o modíolo pode ser visualizado. Na próxima superfície, representada pela Figura 25, não se visualiza o modíolo definindo o início do segmento 2 .

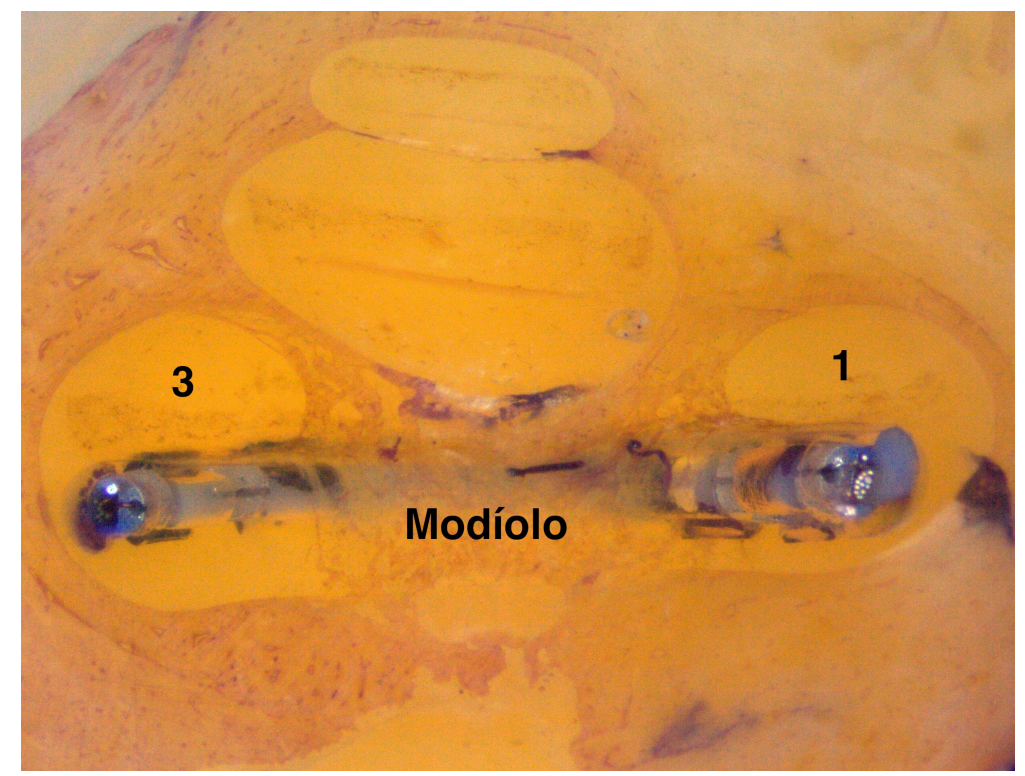

Figura 24 - Visualização dos segmentos 1, 3 e modíolo (Estereomicroscópio Discovery V8 ${ }^{\circledR}$ - Carl Zeiss, Göttingen, Alemanha. Aumento de 15x. Coloração azul de toluidina O)

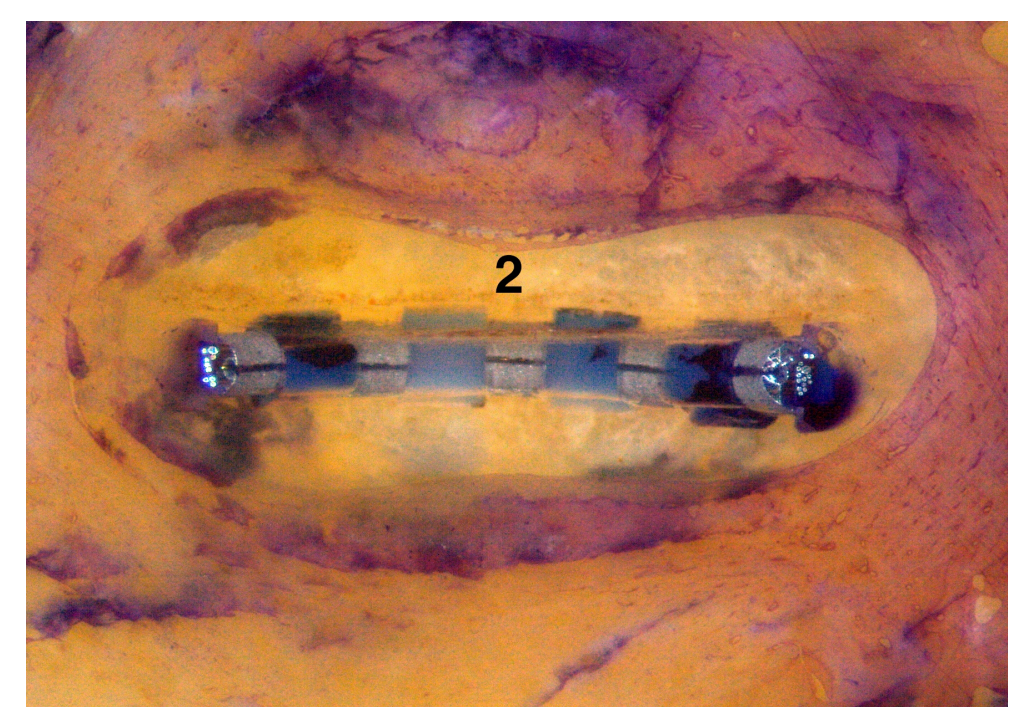

Figura 25 - Visualização do início do segmento 2. O modíolo não é mais visualizado (Estereomicroscópio Discovery V8 ${ }^{\circledR}$ - Carl Zeiss, Göttingen, Alemanha. Aumento de 15x. Coloração azul de toluidina O) 
Obteve-se um total de 372 superfícies para análise histológica. Dessas, nenhuma foi excluída por artefatos que impedissem a identificação das estruturas intracocleares. Na Tabela 4, pode ser vista a quantidade de superfícies em cada um dos ossos temporais e, que é estatisticamente a mesma nos dois grupos $(p=0,936)$.

Tabela 4 - Quantidade de superfícies por peça em cada um dos grupos de ossos temporais e resultados dos testes comparativos

\begin{tabular}{|c|c|c|c|c|}
\hline Variável & $\begin{array}{l}\text { Grupo } 1 \\
(n=13)\end{array}$ & $\begin{array}{c}\text { Grupo } 2 \\
(n=12)\end{array}$ & $\begin{array}{l}\text { TOTAL } \\
(n=25)\end{array}$ & $\mathbf{P}^{1}$ \\
\hline \multicolumn{4}{|c|}{ Quantidade de superfícies por osso temporal } & 0,936 \\
\hline Média \pm DP & $14,8 \pm 3$ & $15 \pm 1,7$ & $14,9 \pm 2,4$ & \\
\hline Mediana (mín.; máx.) & $16(10 ; 21)$ & $15(12 ; 18)$ & $15(10 ; 21)$ & \\
\hline
\end{tabular}

$\mathrm{n}=$ quantidade de ossos

$p=$ nível descritivo

$\mathrm{DP}=$ desvio padrão

mín. = mínimo

máx. = máximo

${ }^{1}$ teste de Mann-Whitney

Todos os graus de trauma, conforme a classificação de Eshraghi et al. ${ }^{30}$ (Tabela 1), foram encontrados em pelo menos uma superfície. Quando, no mesmo segmento, foram observados mais do que um grau de trauma, optou-se por considerar o trauma com grau mais elevado.

As Figuras 26 a 30 mostram imagens das superfícies histológicas que exemplificam os graus de trauma intracoclear conforme a classificação utilizada $^{30}$. 


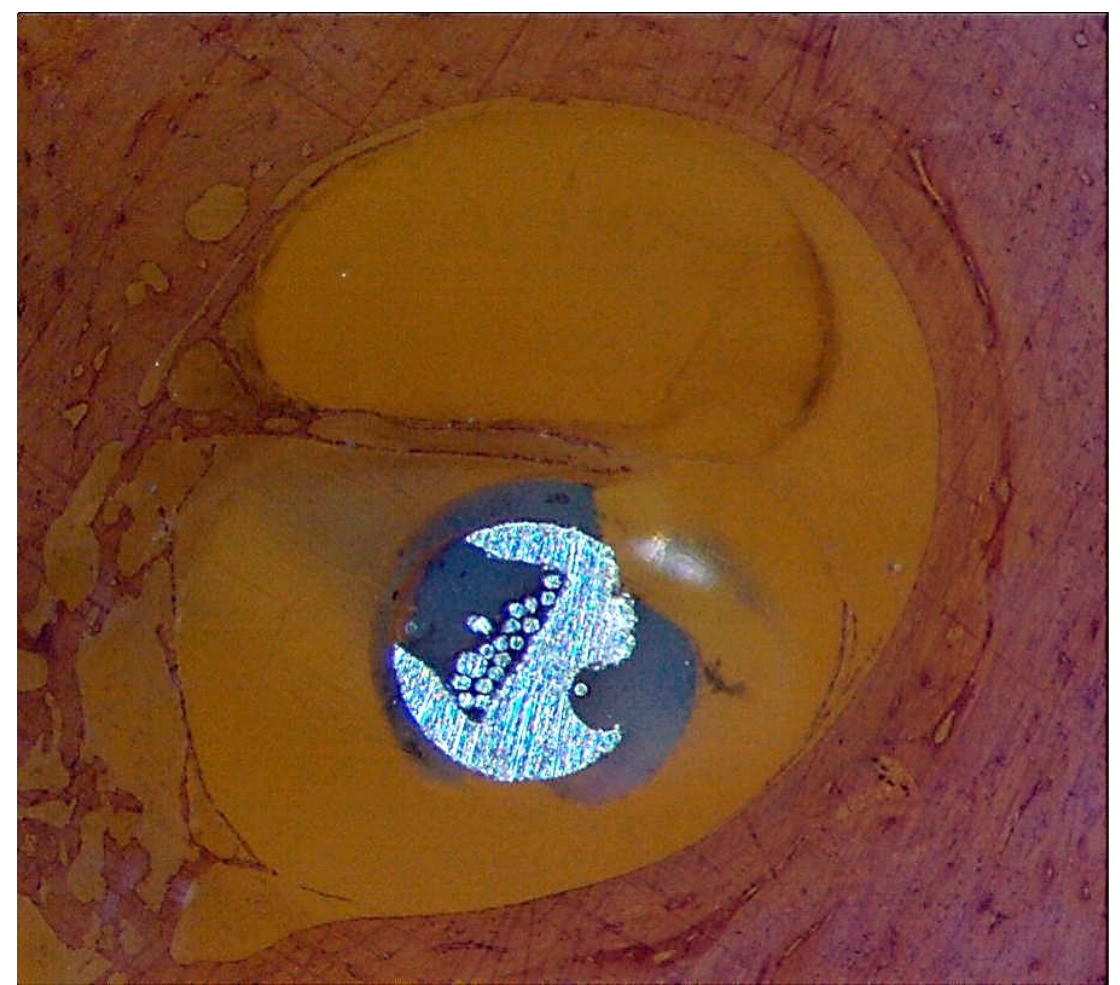

Figura 26 - Feixe de eletrodos posicionado na escala timpânica. Estruturas intracocleares preservadas (Grau 0) (Estereomicroscópio Discovery V8 ${ }^{\circledR}$ - Carl Zeiss, Göttingen, Alemanha. Aumento de 60x. Coloração azul de toluidina $\mathrm{O}$ )

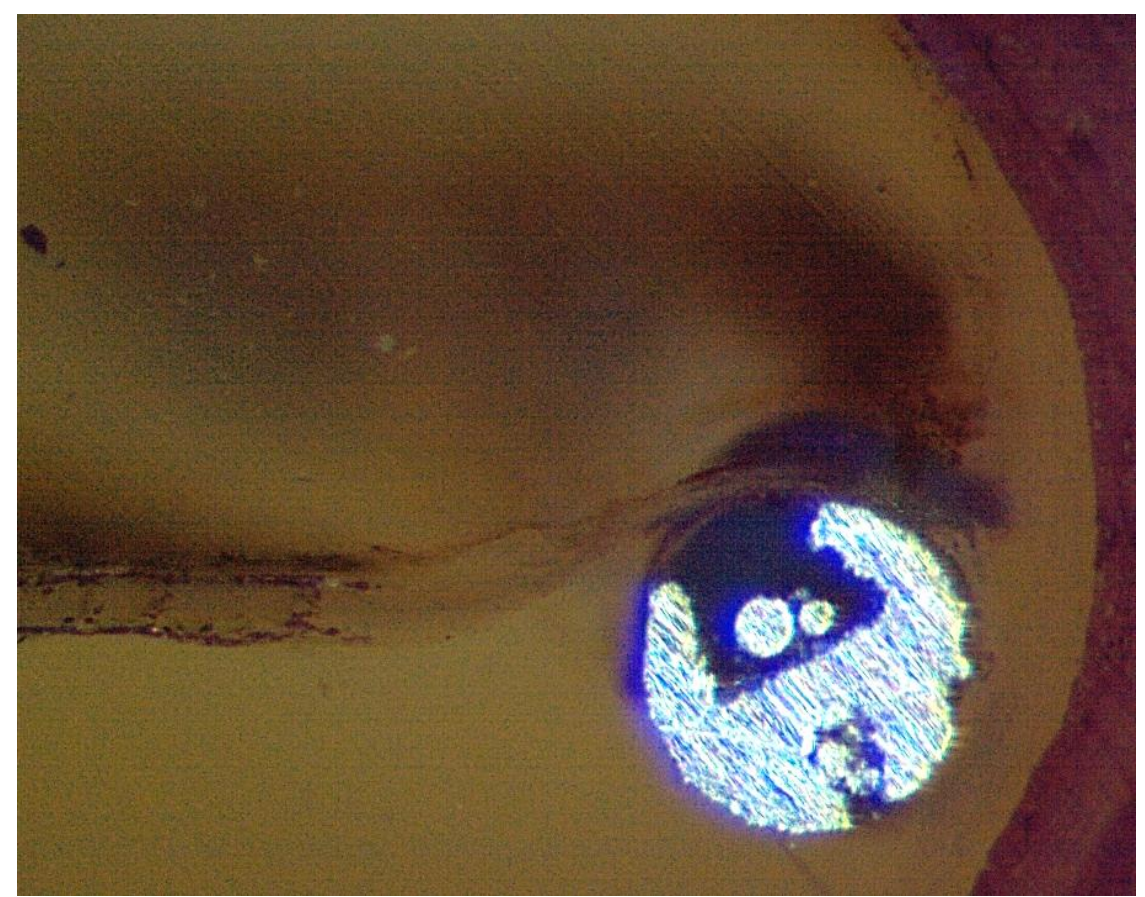

Figura 27 - Feixe de eletrodos na escala timpânica causando discreta elevação da membrana basilar (Grau 1) (Estereomicroscópio Discovery V8 ${ }^{\circledR}$ Carl Zeiss, Göttingen, Alemanha. Aumento de 120x. Coloração azul de toluidina O) 


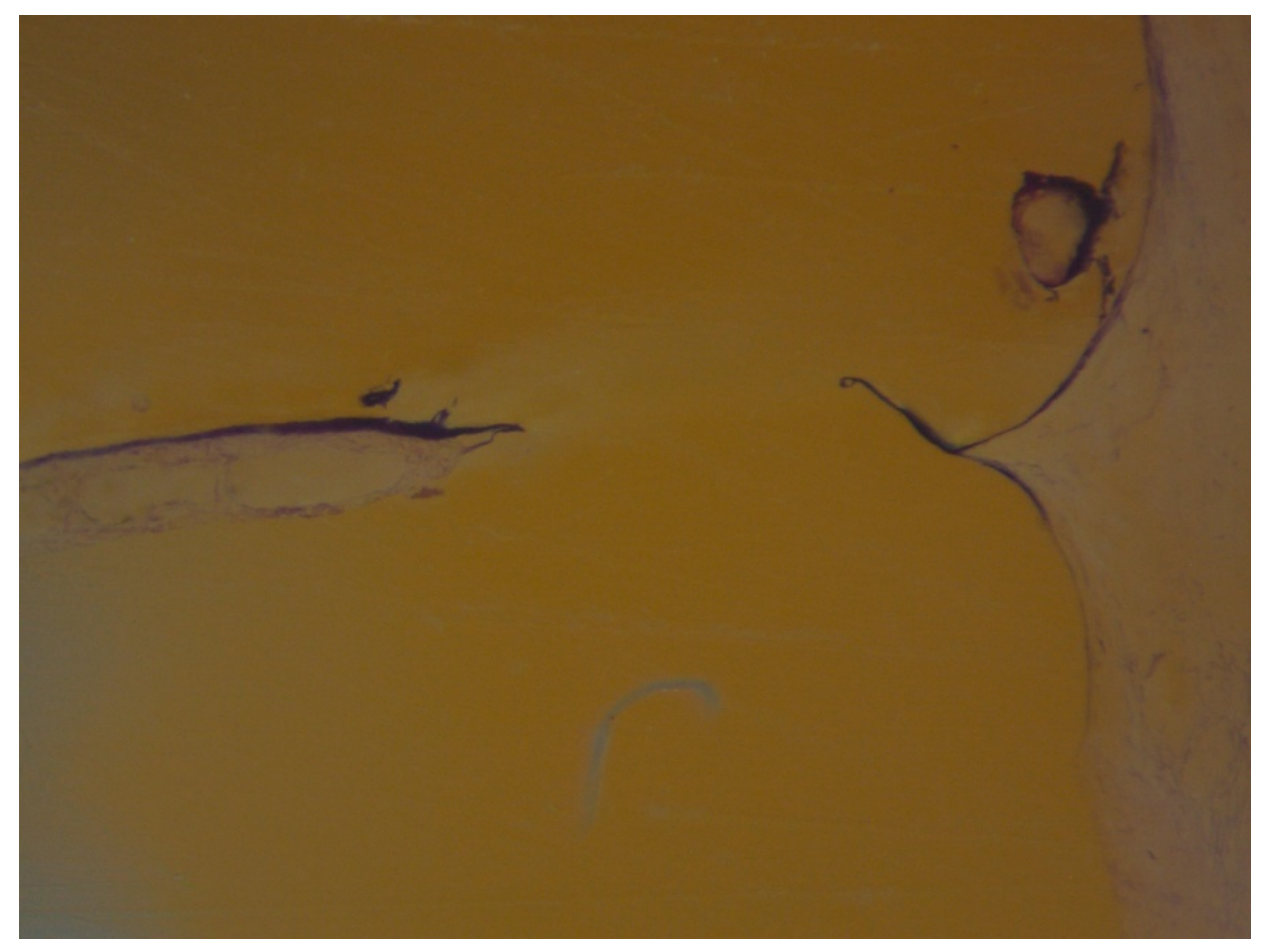

Figura 28 - Identificação de ruptura de membrana basilar (Grau 2) (Estereomicroscópio Discovery $\mathrm{V}^{\circledR}{ }^{\circledR}$ - Carl Zeiss, Göttingen, Alemanha. Aumento de 94x. Coloração azul de toluidina O)

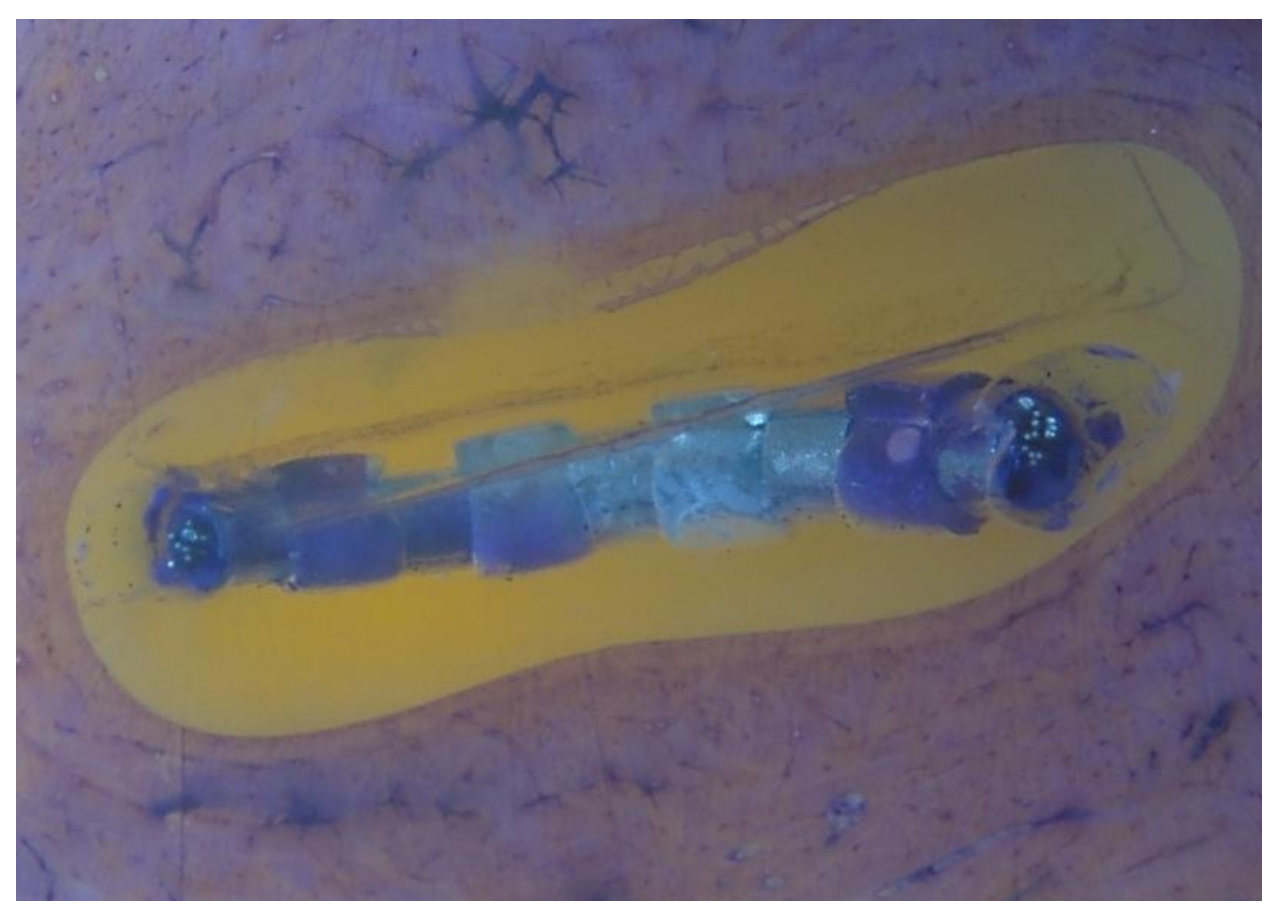

Figura 29 - Deslocamento do feixe de eletrodos da escala timpânica para escala vestibular (Grau 3) (Estereomicroscópio Discovery V8 ${ }^{\circledR}$ - Carl Zeiss, Göttingen, Alemanha. Aumento de 15x. Coloração azul de toluidina O) 


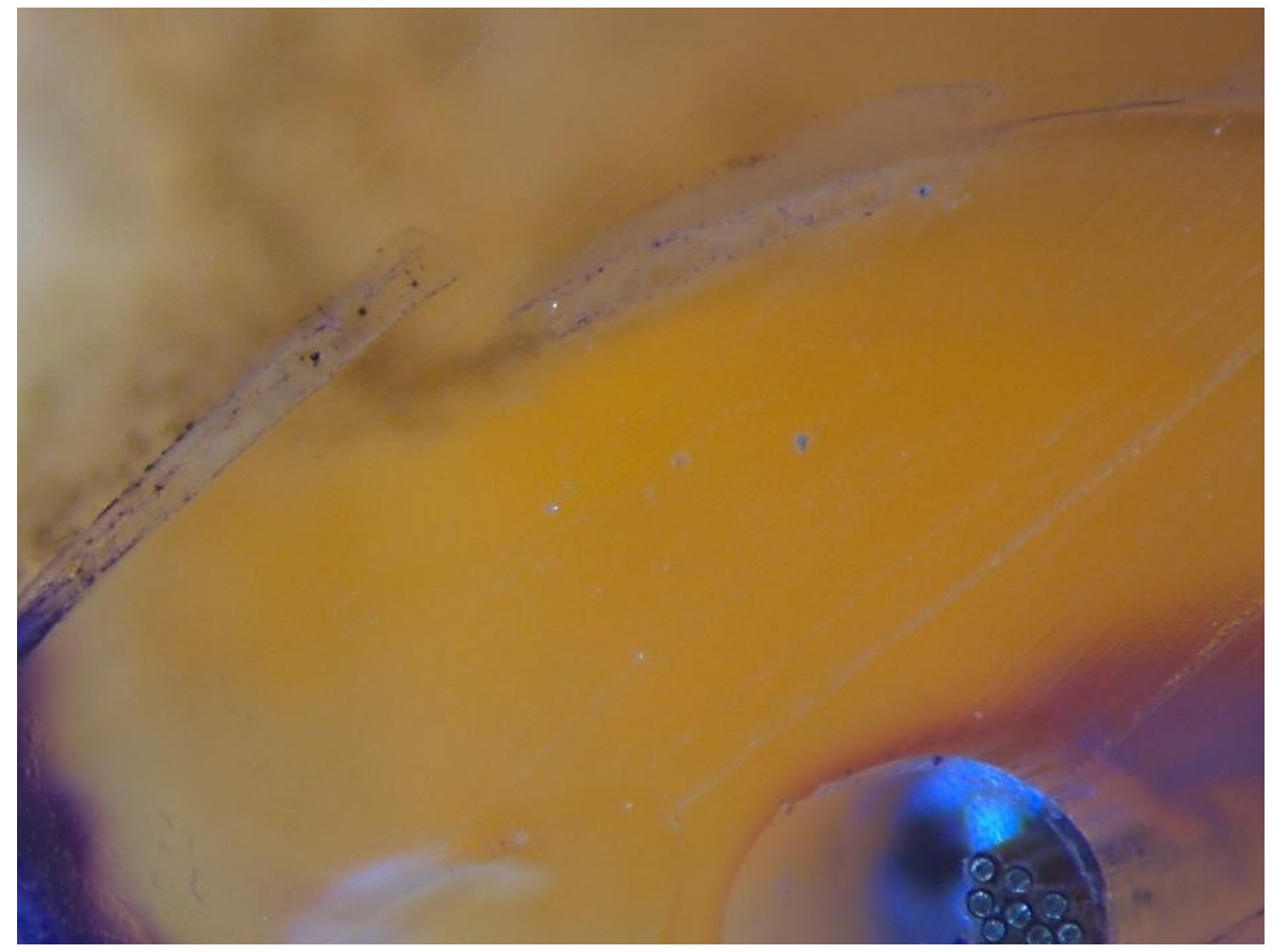

Figura 30 - Identificação de fratura da lâmina espiral óssea (Grau 4) (Estereomicroscópio Discovery $\mathrm{V}^{\circledR}{ }^{\circledR}$ - Carl Zeiss, Göttingen, Alemanha. Aumento de 60x. Coloração azul de toluidina O)

Foram realizadas duas análises referentes à presença de trauma intracoclear, em cada um dos segmentos, nos dois grupos. Na primeira, foram considerados traumas positivos qualquer grau diferente de zero (Tabela 5). Em uma segunda análise, como em outros estudos ${ }^{17}$, foram considerados traumas positivos os graus 2, 3, 4 excluindo-se o grau 1, que representa apenas elevação da membrana basilar (Tabela 6).

As Tabelas 5 e 6 mostram que a presença de trauma intracoclear em qualquer segmento, por ambos os critérios adotados, não apresentou associação estatisticamente significativa com nenhum dos dois grupos ( $p$ > 0,05), ou seja, a inserção do feixe de eletrodos via quadrante 
anterossuperior ou anteroinferior da membrana da JR acarretaram a mesma frequência de trauma nos segmentos.

Tabela 5 - Descrição da presença de trauma intracoclear, considerando trauma positivo qualquer grau diferente de zero, em cada um dos segmentos nos dois grupos e resultados dos testes de associação

\begin{tabular}{|c|c|c|c|c|c|c|c|}
\hline \multirow{3}{*}{ Variável } & \multicolumn{4}{|c|}{ Inserção } & \multirow{2}{*}{\multicolumn{2}{|c|}{$\begin{array}{l}\text { TOTAL } \\
(n=25)\end{array}$}} & \multirow{3}{*}{$\mathbf{P}^{1}$} \\
\hline & \multicolumn{2}{|c|}{$\begin{array}{c}\text { Grupo } 1 \\
(n=13)\end{array}$} & \multicolumn{2}{|c|}{$\begin{array}{c}\text { Grupo } 2 \\
(n=12)\end{array}$} & & & \\
\hline & $\mathbf{n}$ & $\%$ & $\mathbf{n}$ & $\%$ & $\mathbf{n}$ & $\%$ & \\
\hline Segmento 1 & & & & & & & 0,220 \\
\hline Negativo & 13 & 100,0 & 10 & 83,3 & 23 & 92,0 & \\
\hline Positivo $^{2}$ & 0 & 0,0 & 2 & 16,7 & 2 & 8,0 & \\
\hline Segmento 2 & & & & & & & 0,673 \\
\hline Negativo & 10 & 76,9 & 8 & 66,7 & 18 & 72,0 & \\
\hline Positivo $^{2}$ & 3 & 23,1 & 4 & 33,3 & 7 & 28,0 & \\
\hline Segmento 3 & & & & & & & 0,688 \\
\hline Negativo & 9 & 69,2 & 7 & 58,3 & 16 & 64,0 & \\
\hline Positivo $^{2}$ & 4 & 30,8 & 5 & 41,7 & 9 & 36,0 & \\
\hline Segmento 4 & & & & & & & $>0,999$ \\
\hline Negativo & 11 & 84,6 & 10 & 83,3 & 21 & 84,0 & \\
\hline Positivo $^{2}$ & 2 & 15,4 & 2 & 16,7 & 4 & 16,0 & \\
\hline Segmento 5 & & & & & & & $>0,999$ \\
\hline Negativo & 10 & 76,9 & 9 & 75,0 & 19 & 76,0 & \\
\hline Positivo $^{2}$ & 3 & 23,1 & 3 & 25,0 & 6 & 24,0 & \\
\hline Qualquer segmento & & & & & & & 0,688 \\
\hline Negativo & 9 & 69,2 & 7 & 58,3 & 16 & 64,0 & \\
\hline Positivo $^{2}$ & 4 & 30,8 & 5 & 41,7 & 9 & 36,0 & \\
\hline
\end{tabular}

$\mathrm{n}=$ quantidade de ossos

$\%=$ porcento

$\mathrm{p}=$ nível descritivo

${ }^{1}$ Resultado do teste exato de Fisher

2 Qualquer grau 
Tabela 6 - Descrição da presença de trauma intracoclear, considerando trauma positivo os graus 2, 3 e 4 em cada um dos segmentos nos dois grupos e resultados dos testes de associação

\begin{tabular}{|c|c|c|c|c|c|c|c|}
\hline \multirow{3}{*}{ Variável } & \multicolumn{4}{|c|}{ Inserção } & \multirow{2}{*}{\multicolumn{2}{|c|}{$\begin{array}{c}\text { TOTAL } \\
(n=25)\end{array}$}} & \multirow{3}{*}{$\mathbf{P}^{1}$} \\
\hline & \multicolumn{2}{|c|}{$\begin{array}{c}\text { Grupo } 1 \\
(n=13)\end{array}$} & \multicolumn{2}{|c|}{$\begin{array}{c}\text { Grupo } 2 \\
(n=12)\end{array}$} & & & \\
\hline & $\mathbf{n}$ & $\%$ & $\mathbf{n}$ & $\%$ & $\mathbf{n}$ & $\%$ & \\
\hline Segmento 1 & & & & & & & 0,220 \\
\hline Negativo (0 e 1) & 13 & 100,0 & 10 & 83,3 & 23 & 92,0 & \\
\hline Positivo (2, 3 e 4$)$ & 0 & 0,0 & 2 & 16,7 & 2 & 8,0 & \\
\hline Segmento 2 & & & & & & & 0,378 \\
\hline Negativo & 11 & 84,6 & 8 & 66,7 & 19 & 76,0 & \\
\hline Positivo (2, 3 e 4$)$ & 2 & 15,4 & 4 & 33,3 & 6 & 24,0 & \\
\hline Segmento 3 & & & & & & & 0,202 \\
\hline Negativo (0 e 1) & 11 & 84,6 & 7 & 58,3 & 18 & 72,0 & \\
\hline Positivo (2, 3 e 4 ) & 2 & 15,4 & 5 & 41,7 & 7 & 28,0 & \\
\hline Segmento 4 & & & & & & & 0,593 \\
\hline Negativo (0 e 1) & 12 & 92,3 & 10 & 83,3 & 22 & 88,0 & \\
\hline Positivo (2, 3 e 4 ) & 1 & 7,7 & 2 & 16,7 & 3 & 12,0 & \\
\hline Segmento 5 & & & & & & & 0,645 \\
\hline Negativo (0 e 1) & 11 & 84,6 & 9 & 75,0 & 20 & 80,0 & \\
\hline Positivo (2, 3 e 4$)$ & 2 & 15,4 & 3 & 25,0 & 5 & 20,0 & \\
\hline Qualquer segmento & & & & & & & 0,411 \\
\hline Negativo (0 e 1) & 10 & 76,9 & 7 & 58,3 & 17 & 68,0 & \\
\hline Positivo (2, 3 e 4$)$ & 3 & 23,1 & 5 & 41,7 & 8 & 32,0 & \\
\hline
\end{tabular}

$\mathrm{n}=$ quantidade de ossos

$\%=$ porcento

$\mathrm{p}=$ nível descritivo

${ }^{1}$ Resultado do teste exato de Fisher

Os graus de trauma intracoclear, em cada um dos segmentos, foi estatisticamente igual em ambos os grupos $(p>0,05)$ (Tabela 7$)$. 
Tabela 7 - Descrição do grau de trauma em cada um dos segmentos nos dois grupos e resultado dos testes comparativos

\begin{tabular}{|c|c|c|c|c|c|c|c|}
\hline \multirow{3}{*}{ Variável } & \multicolumn{4}{|c|}{ Inserção } & \multirow{2}{*}{\multicolumn{2}{|c|}{$\begin{array}{l}\text { TOTAL } \\
(n=25)\end{array}$}} & \multirow{3}{*}{$\mathbf{P}^{1}$} \\
\hline & \multicolumn{2}{|c|}{$\begin{array}{c}\text { Grupo } 1 \\
(n=13)\end{array}$} & \multicolumn{2}{|c|}{$\begin{array}{c}\text { Grupo } 2 \\
(n=12)\end{array}$} & & & \\
\hline & $n$ & $\%$ & $n$ & $\%$ & $n$ & $\%$ & \\
\hline Segmento 1 (grau) & & & & & & & 0,503 \\
\hline 0 & 13 & 100,0 & 10 & 83,3 & 23 & 92,0 & \\
\hline 1 & 0 & 0,0 & 0 & 0,0 & 0 & 0,0 & \\
\hline 2 & 0 & 0,0 & 0 & 0,0 & 0 & 0,0 & \\
\hline 3 & 0 & 0,0 & 0 & 0,0 & 0 & 0,0 & \\
\hline 4 & 0 & 0,0 & 2 & 16,7 & 2 & 8,0 & \\
\hline Segmento 2 (grau) & & & & & & & 0,538 \\
\hline 0 & 10 & 76,9 & 8 & 66,7 & 18 & 72,0 & \\
\hline 1 & 1 & 7,7 & 0 & 0,0 & 1 & 4,0 & \\
\hline 2 & 1 & 7,7 & 1 & 8,3 & 2 & 8,0 & \\
\hline 3 & 1 & 7,7 & 1 & 8,3 & 2 & 8,0 & \\
\hline 4 & 0 & 0,0 & 2 & 16,7 & 2 & 8,0 & \\
\hline Segmento 3 (grau) & & & & & & & 0,470 \\
\hline 0 & 9 & 69,2 & 7 & 58,3 & 16 & 64,0 & \\
\hline 1 & 2 & 15,4 & 0 & 0,0 & 2 & 8,0 & \\
\hline 2 & 1 & 7,7 & 2 & 16,7 & 3 & 12,0 & \\
\hline 3 & 0 & 0,0 & 0 & 0,0 & 0 & 0,0 & \\
\hline 4 & 1 & 7,7 & 3 & 25,0 & 4 & 16,0 & \\
\hline Segmento 4 (grau) & & & & & & & 0,894 \\
\hline 0 & 11 & 84,6 & 10 & 83,3 & 21 & 84,0 & \\
\hline 1 & 1 & 7,7 & 0 & 0,0 & 1 & 4,0 & \\
\hline 2 & 0 & 0,0 & 0 & 0,0 & 0 & 0,0 & \\
\hline 3 & 1 & 7,7 & 1 & 8,3 & 2 & 8,0 & \\
\hline 4 & 0 & 0,0 & 1 & 8,3 & 1 & 4,0 & \\
\hline Segmento 5 (grau) & & & & & & & 0,810 \\
\hline 0 & 10 & 76,9 & 9 & 75,0 & 19 & 76,0 & \\
\hline 1 & 1 & 7,7 & 0 & 0,0 & 1 & 4,0 & \\
\hline 2 & 0 & 0,0 & 0 & 0,0 & 0 & 0,0 & \\
\hline 3 & 1 & 7,7 & 0 & 0,0 & 1 & 4,0 & \\
\hline 4 & 1 & 7,7 & 3 & 25,0 & 4 & 16,0 & \\
\hline Pior grau & & & & & & & 0,406 \\
\hline 0 & 9 & 69,2 & 7 & 58,3 & 16 & 64,0 & \\
\hline 1 & 1 & 7,7 & 0 & 0,0 & 1 & 4,0 & \\
\hline 2 & 1 & 7,7 & 0 & 0,0 & 1 & 4,0 & \\
\hline 3 & 1 & 7,7 & 0 & 0,0 & 1 & 4,0 & \\
\hline 4 & 1 & 7,7 & 5 & 41,7 & 6 & 24,0 & \\
\hline
\end{tabular}


6 DISCUSSÃO 


\section{DISCUSSÃO}

Dentre os cinco sentidos, a audição é o mais importante para a comunicação. A comunicação é essencial para a interação do indivíduo com a sociedade. Antes mesmo do nascimento, o ser humano interage com $o$ ambiente por meio da audição. Pesquisas demonstraram reações fetais reativas a estímulos sonoros a partir da $16^{\mathrm{a}}$ semana de gestação ${ }^{55}$.

A perda de audição é um problema de saúde epidemiologicamente relevante em todo mundo. Há séculos são reconhecidos os prejuízos que a perda de audição pode causar, e existem numerosos relatos de diferentes formas de reabilitação.

Por muito tempo, a tecnologia disponível para a reabilitação de pacientes com perda de audição severa ou profunda era insuficiente para o desenvolvimento de linguagem oral. Porém, nos últimos 40 anos, houve progresso considerável nessa área, mediante a utilização dos ICs. Os ICs são sistemas protéticos semi-implantáveis, que por meio de eletrodos intracocleares, cirurgicamente implantados, estimulam elementos neurais do sistema auditivo.

Desde a sua criação, os critérios de indicação de IC sofreram inúmeras modificações. Atualmente, são muito mais abrangentes do que os apresentados em 1984, quando o aparelho House $/ 3 \mathrm{M}^{\circledR}$ (Los Angeles, EUA) foi aprovado pelo Food and Drug Administration (FDA) para ser utilizado em adultos pós-linguais, com perda de audição profunda bilateral ${ }^{56}$. Os motivos 
destas modificações foram os bons resultados auditivos obtidos em pacientes com IC, em comparação aos resultados com $\mathrm{AAS}^{57}$. Como a evolução tecnológica é claramente identificável, em muitas das nossas tarefas diárias, é fácil associar estes resultados somente aos avanços tecnológicos dos $\mathrm{ICs}^{58}$. Porém, deve-se lembrar que, com a expansão dos critérios de indicação, é cada vez maior a quantidade de pacientes implantados com audição residual. Este fato sugere analisar a evolução dos critérios de indicação de forma cíclica, pois os bons resultados obtidos com o IC são causa e consequência da quantidade crescente de pacientes implantados com audição residual ${ }^{59,60}$. Estes pacientes justificam que a preservação da audição residual no pós-operatório seja, atualmente, uma das prioridades dos cirurgiões de IC.

No início, o sacrifício da audição residual era considerado aceitável, como uma consequência inevitável da inserção do feixe de eletrodos na orelha interna. Atualmente, apesar de imprevisível, a preservação da audição residual é uma meta realista ${ }^{25-27}$. Diversos estudos sugerem, não apenas a sobrevivência das células ciliadas, como também, o funcionamento das mesmas com sensibilidade quase normal ${ }^{22,24}$. Entre as vantagens de preservar a audição residual está a possibilidade de EEA da cóclea. Os candidatos à EEA são pacientes com audição preservada em frequências baixas e perda de audição moderada a severa em frequências moderadas a $\operatorname{altas}^{28}$. Algumas das vantagens da EEA são o melhor reconhecimento da fala em ambientes ruidosos ${ }^{61-65}$ e melhor apreciação musical ${ }^{66}$. No entanto, mesmo com a quantidade crescente de candidatos à IC com audição 
residual, os benefícios da EEA ainda são restritos a um grupo reduzido de pacientes que apresentam restos auditivos acusticamente estimuláveis. Por este motivo, surgiu o questionamento se a preocupação com a preservação da audição residual e a utilização de técnicas cirúrgicas atraumáticas são justificáveis para todos os pacientes candidatos a $\mathrm{IC}^{9}$. Alguns argumentos que sustentam estas preocupações são:

1. Melhores resultados obtidos com a utilização isolada do IC, em pacientes com audição residual preservada no pós-operatório ${ }^{10,28}$;

2. Associação entre trauma intracoclear e preservação da audição residual $^{9,10,33,34}$

3. Preservação da anatomia coclear. A preservação da anatomia intracoclear ganhou destaque com a diminuição progressiva da idade das crianças implantadas. Atualmente crianças com menos de 1 ano de idade são implantadas. Os ICs atuais têm durabilidade de décadas, porém, espera-se que pacientes muito jovens sejam submetidos a cirurgias revisionais, em algum momento de suas vidas. Nestes casos, o reimplante pode ser problemático se a primeira cirurgia tiver traumatizado as estruturas intracocleares. Além disso, cócleas anatomicamente preservadas terão maior probabilidade de serem beneficiadas com tecnologias futuras, como as terapias com células tronco ${ }^{29,41}$;

4. Associação entre trauma intracoclear e preservação da audição residual com fibrose e neoformação óssea ${ }^{39,45,46,47,48}$; 
5. Associação entre trauma intracoclear e degeneração retrógrada ${ }^{23,}$ 39,40

Até hoje, muitos passos da cirurgia atraumática provém do artigo de Lehnhardt ${ }^{42}$ de 1993. São apoiados em princípios de senso comum sobre a abertura e manipulação das estruturas da orelha média e interna, e aprendizados de outras cirurgias otológicas, como as estapedotomias, por exemplo. O propósito inicial da cirurgia atraumática era evitar trauma mecânico e penetração de substâncias que podem causar reações intracocleares adversas. Com o passar dos anos, outros objetivos foram incorporados como: diminuir a reação inflamatória, a fibrose e a neoformação óssea, evitar trauma acústico, evitar alterações do potencial endococlear e diminuir respostas moleculares, como apoptose celular. Todas essas metas visam, além de evitar a perda da audição residual imediata e tardia, manter a anatomia intracoclear intacta, evitar degeneração retrograda e melhorar o desempenho auditivo.

A via de inserção do feixe de eletrodos é considerada um passo essencial para uma cirurgia atraumática. Inúmeros autores compararam as vantagens e desvantagens da inserção do feixe de eletrodos do IC via cocleostomias ou $\mathrm{JR}^{17-21}$ e mais especificamente, por cocleostomias confeccionadas em diferentes localizações ${ }^{43,45,48}$.

Cocleostomias na região inferior da JR são consideradas menos traumáticas, menos associadas a posicionamentos inadvertidos do feixe de eletrodos na escala média ou vestibular, e apresentam porcentagens maiores de preservação da audição residual quando comparadas às 
cocleostomias localizadas na região superior, anterior e ate mesmo anteroinferior à $\mathrm{JR}^{45,46,48,51,67}$. Ao observar estes estudos, que identificaram diferenças no trauma intracoclear e no desempenho audiológico nas diferentes posições da cocleostomia, o grupo de implante coclear do HCFMUSP questionou se o trauma intracoclear é diferente quando o feixe de eletrodos é inserido por diferentes localizações na JR.

Neste estudo, escolheu-se a metade anterior da membrana da JR para a inserção do feixe de eletrodos, apoiada em estudos anatômicos que descrevem a proximidade da metade posterior da membrana da JR com a lâmina espiral óssea e a difícil visualização desta parte da membrana, graças a sua orientação horizontal ${ }^{8,46,51}$. Optou-se, assim, comparar os quadrantes anterossuperior e anteroinferior.

Durante as cirurgias efetuadas no presente estudo, em todas as peças foram observadas projeções ósseas do nicho da JR que limitavam a visualização de sua membrana. Em virtude das discrepâncias existentes na literatura em relação à nomenclatura destas projeções ${ }^{51}$ optou-se por denominá-las conforme as suas localizações anatômicas em relação à membrana da JR. Foram realizados broqueamentos das projeções ósseas anterior e anteroinferior, e discreto broqueamento da projeção óssea posterior. Estes resultados estão em concordância com estudos anatômicos anteriores $^{5,50}$, entre eles pode-se destacar Roland et al. ${ }^{46}$, que, em 2007, realizaram a dissecção de 30 ossos temporais e observaram projeções anatômicas que limitavam a visualização da membrana da JR em todas as peças. Optou-se pela não obrigatoriedade de visualização da metade 
posterior da membrana. O intuito do broqueamento da projeção posterior foi apenas para melhorar a exposição da metade anterior e facilitar o ângulo de inserção do feixe de eletrodos. Em nenhuma das peças pode-se excluir totalmente a necessidade de broqueamento do promontório, no entanto, a quantidade de broqueamento necessária foi mínima. Takahashi e Sando ${ }^{68}$, estimam que, para a inserção do feixe de eletrodos via JR é necessária a remoção de menos de $1 \mathrm{~mm}$ de osso. Esse broqueamento é menor do que o necessário para a confecção da cocleostomia, diminuindo a possibilidade de traumas $^{19,44}$.

A análise estatística do presente estudo foi bicaudal, pois previamente não se obteve dados suficientes que sugerissem qual seria a direção dos resultados. De fato, como é explicado mais adiante, os dados disponíveis na literatura podem ser interpretados de formas conflitantes. A hipótese de o trauma intracoclear ser menor com a inserção do feixe de eletrodos através do quadrante anteroinferior da membrana da JR surgiu por causa da proximidade anatômica deste quadrante com a região inferior à JR, localização atualmente considerada menos traumática para a confecção da cocleostomia e inserção do feixe de eletrodos ${ }^{45}$. Por outro lado, em razão do trajeto descendente da escala timpânica a partir da JR, na inserção via quadrante anteroinferior, a probabilidade do feixe de eletrodos ser direcionada superiormente, em direção às estruturas do teto da escala timpânica, é maior ${ }^{46,52}$. Este fato sugere a hipótese do trauma intracoclear ser maior quando o feixe de eletrodos é inserido pelo quadrante anteroinferior. 
Meshik et al. ${ }^{47}$, em 2010, referiram que nas cocleostomias localizadas na margem inferior da JR, muitas vezes o vetor de inserção do feixe de eletrodos toca o segmento mastoídeo do nervo facial, ou até mesmo secciona-o. Briggs et al. $^{45}$, em 2006, descreveram que a cocleostomia na região inferior da JR necessita de completa esqueletização do nervo facial e corda do tímpano, procedimento que desencoraja muitos cirurgiões a realizá-la em tal localização. No presente estudo, optou-se pela visualização completa da metade anterior da membrana da JR, em todas as peças. Para a exposição do quadrante anteroinferior foi necessária a ampliação da timpanotomia posterior, com esqueletização da porção mastoídea do nervo facial em algumas peças. Tal esqueletização não seria necessária se o objetivo fosse visualizar somente o quadrante anterossuperior. Esta observação corrobora com os estudos acima citados. Apesar de tais estudos não utilizarem a JR como via de inserção, a cocleostomia na borda inferior da JR necessita da mesma exposição cirúrgica que a inserção via quadrante anteroinferior da membrana da JR. Os resultados do presente estudo não mostraram diferenças estatisticamente significantes no trauma intracoclear, quando o feixe de eletrodos é inserido pelos quadrantes comparados. Assim, sugere-se que cirurgiões que não se sentirem confortáveis para a realização de uma dissecção mais extensa do nervo facial para visualização do quadrante anteroinferior, podem optar pela inserção do feixe de eletrodos pelo quadrante anterossuperior, que requer uma exposição mais conservadora. 
O escopo deste estudo não é avaliar a profundidade de inserção do feixe de eletrodos. Por isso, optou-se por padronizar as áreas da cóclea por uma forma mais visual, do que adotar uma segmentação em graus de inserção do feixe de eletrodos, que poderia ser obtida por meio de análises das TCs.

Foram utilizados ossos temporais frescos congelados, excisados até 24 horas após a morte, para manter as propriedades dos tecidos vivos ${ }^{69}$. Na literatura já foram descritas diferentes técnicas de preparo de ossos temporais implantados. Em algumas técnicas é necessário remover o feixe de eletrodos antes do preparo do osso para a análise histológica. Em outras, realiza-se esqueletização da cóclea para a visualização da posição do feixe de eletrodos e de traumas nas estruturas intracocleares. Autores contrários a estas técnicas alegam que o próprio broqueamento para a esqueletização da cóclea, ou a remoção do feixe de eletrodos, podem ser responsáveis por lesões em estruturas intracocleares ${ }^{70}$.

No presente estudo, adotou-se o método de preparo dos ossos temporais proposto por Plenk ${ }^{71}$, em 1986. Esta técnica permite a preparação, e a secção dos ossos temporais não descalcificados, com o feixe de eletrodos in situ. O osso temporal implantado, e embebido em resina, é progressivamente polido permitindo que cada superfície exposta seja corada e analisada. A excelente imagem proporcionada possibilita a clara identificação de estruturas intracocleares, do feixe de eletrodos e da relação destes dois componentes ${ }^{71}$. Este tipo de preparo não elimina a possibilidade de artefatos, porém se mostrou efetivo em diversos 
trabalhos $^{72}$. No presente trabalho, nenhuma superfície pós-polimento apresentou artefatos que impedissem a identificação e análise das estruturas intracocleares em estudo. São consideradas desvantagens desta técnica de preparo, o tempo necessário para completar todo o processo em cada peça e o alto custo dos equipamentos ${ }^{71}$.

Optou-se pelo sistema de classificação proposto por Eshraghi et al. ${ }^{30}$, em 2003, para padronizar a análise histológica. Considera-se uma falha desta classificação que, as consequências funcionais negativas geradas por um trauma intracoclear podem não evoluir de acordo com a numeração ascendente da classificação. Como exemplo, pode-se citar um trauma grau 4, por causa de uma fratura na lâmina espiral óssea. Embora este trauma altere as funções cocleares na região afetada, provavelmente não interfere nos gradientes dos íons e na hemodinâmica dos líquidos intracocleares. Por outro lado, um trauma grau 2, ocasionado por ruptura da membrana basilar, presumivelmente leva a danos intracocleares mais dispersos. Isto ocorre porque, este tipo de trauma gera a mistura de endolinfa e perilinfa, alterando o gradiente normal dos íons, que pode levar à degeneração das células ciliadas e estruturas neurais. Por causa do fluxo endococlear, toda a cóclea pode ser comprometida ${ }^{31,32}$. 


\section{CONCLUSÕES}




\section{CONCLUSÕES}

Neste estudo não houve diferença estatisticamente significativa na presença de trauma intracoclear, e na severidade dos traumas ocorridos na inserção do feixe de eletrodos do IC pelo quadrante anterossuperior e anteroinferior da membrana da JR.

Observou-se, porém, maior facilidade para exposição cirúrgica do quadrante anterossuperior em relação ao quadrante anteroinferior.

O preparo histológico de ossos implantados utilizados mostrou ser efetivo. 
8 ANEXO 


\section{ANEXO A}

FICHA DE PROTOCOLO

1. Número do osso temporal

2. Lado

Direito

$\square$ Esquerdo

3. Necessidade de broqueamento de

$\square \operatorname{Sim}$

$\square$ Não

projeções ósseas do nicho da JR

4. Presença de falsa membrana

$\square \operatorname{Sim}$

$\square$ Não

5. Tipo de inserção

$\square$ Completa

$\square$ Parcial 


\section{REFERÊNCIAS}




\section{REFERÊNCIAS ${ }^{1}$}

1. Bento RF, Brito Neto RV, Castilho AM, Goffi Gomez MVS, SantAnna SBG, Guedes MC. Auditory results with multicanal cochlear implant in patients submitted to cochlear implant surgery at University of São Paulo Medical School - Hospital das Clínicas. Rev Bras Otorrinolaringol. 2004;70(5): 632-4.

2. World Health Organizatio. Deafness and hearing loss. [Acesso em: 22 de outubro de 2013] Disponível em:

http://www.who.int/mediacentre/factsheets/fs300/en/;.

3. Baraky LR, Bento RF, Barbosa Raposo NR, Cerrato Tibirica SH, Ribeiro LC, Barone MMVB, Vasconcelos NB. Disabling hearing loss prevalence in Juiz de Fora, Brazil. Braz J Otorhinolaryngol. 2012;78(4):52-8.

4. Wilson BS, Dorman MF. Interfacing sensors with the nervous system: Lessons from the development and success of the cochlear implant. IEEE Sensors J. 2008;8(1-2):131-47.

5. Wilson BS, Dorman MF. Cochlear implants: Current designs and future possibilities. J Rehabil Res Dev. 2008;45(5):695-730.

6. Fayad J, Linthicum FH, Otto SR, Galey FR, House WF. Cochlear implants - Histopathologic findings related to performance in 16 human temporal bones. Ann Otol Rhinol Laryngol. 1991;100(10):807-11.

7. Nadol JB, Shiao JY, Burgess BJ, Ketten DR, Eddington DK, Gantz BJ,Montandon P, Coker NJ, Roland JT Jr, Shallop JK. Histopathology of cochlear implants in humans. Ann Otol Rhinol Laryngol. 2001;110(9):883-91.

8. Franz BK, Clark GM, Bloom DM. Surgical anatomy of the round window with special reference to cochlear implantation. J Laryngol Otol. 1987;101(2):97-102.

\footnotetext{
${ }^{1}$ De acordo com:

Adaptado de International Committee of Medical Journals Editors (Vancouver).

Universidade de São Paulo. Faculdade de Medicina. Serviço de Biblioteca e Documentação. Guia de apresentação de dissertações, teses e monografias da FMUSP. Elaborado por Anneliese Carneiro da Cunha, Maria Julia A.L. Freddi, Maria F. Crestana, Marinalva de S. Aragão, Suely C. Cardoso, Valéria Vilhena. 3a ed. São Paulo: Divisão de Biblioteca e Documentação; 2011.

Abreviaturas dos títulos dos periódicos de acordo com List of Journals Indexed in Index Medicus.
} 
9. Balkany TJ, Connell SS, Hodges AV, Payne SL, Telischi FF, Eshraghi AA, Angeli SI, Germani R, Messiah S, Arheart KL. Conservation of residual acoustic hearing after cochlear implantation. Otol Neurootol. 2006;27(8):1083-8.

10. Carlson ML, Driscoll CLW, Gifford RH, Service GJ, Tombers NM, Hughes-Borst BJ, Neff BA, Beatty CW. Implications of Minimizing Trauma During Conventional Cochlear Implantation. Otol Neurootol. 2011;32(6):962-8.

11. Goffi-Gomez MVS, Guedes MC, Ornelas CG, Sant'anna SBG, Brito Neto RV. Hearing conservation after cochlear implant: pilot study. Rev Bras Otorrinolaringol. 2002;68(5):698-702.

12. Skarzynski H, Lorens A, D'Haese P, Walkowiak A, Piotrowska A, Sliwa L, Anderson I. Preservation of residual hearing in children and post-lingually deafened adults after cochlear implantation: An initial study. ORL J Otorhinolaryngol Relat Spec. 2002;64(4):247-53.

13. James C, Albegger K, Battmer R, Burdo S, Deggouj N, Deguine O, Dillier N, Gersdorff M, Laszig R, Lenarz T, Rodriguez MM, Mondain M, Offeciers E, Macías AR, Ramsden R, Sterkers O, Von Wallenberg E, Weber B, Fraysse B. Preservation of residual hearing with cochlear implantation: How and why. Acta Otolaryngol. 2005;125(5):481-91.

14. Garcia-lbanez L, Macias AR, Morera C, Rodriguez MM, Szyfter W, Skarszynski $\mathrm{H}$, Emamdjomeh $\mathrm{H}$, Baumgartner WD. An evaluation of the preservation of residual hearing with the Nucleus Contour Advance electrode. Acta Otolaryngol. 2009;129(6):651-64.

15. Banfai P. A surgical approach for the cochlear implant (author's transl). HNO. 1978;26(3):85-9.

16. Lenarz T, Stover T, Buechner A, Paasche G, Briggs R, Risi F, et al. Temporal bone results and hearing preservation with a new straight electrode. Audiol Neurootol. 2006;11(Suppl 1):34-41.

17. Adunka O, Gstoettner W, Hambek M, Unkelbach MH, Radeloff A, Kiefer J. Preservation of basal inner ear structures in cochlear implantation. ORL J Otorhinolaryngol Relat Spec. 2004;66(6):306-12.

18. Paprocki A, Biskup B, Kozlowska K, Kuniszyk A, Bien D, Niemczyk K. The topographical anatomy of the round window and related structures for the. Folia Morphol. 2004;63(3):309-12.

19. Adunka O, Kiefer J, Unkelbach MH, Lehnert T, Gstoettner W. Development and evaluation of an improved cochlear implant electrode design for electric acoustic stimulation. Laryngoscope. 2004;114:123741.

20. Pau HW, Just T, Bornitz M, Lasurashvilli N, Zahnert T. Noise exposure of the inner ear during drilling a cochleostomy for cochlear implantation. Laryngoscope. 2007;117(3):535-40. 
21. Connor SE, Holland NJ, Agger A, Leong AC, Varghese RA, Jiang D, Fitzgerald O'Connor A. Round window electrode insertion potentiates retention in the scala tympani. Acta Otolaryngol. 2012;132(9):932-7.

22. Ni DF, Shepherd RK, Seldon HL, Xu SA, Clark GM, Millard RE. Cochlear pathology following chronic electrical-stimulation of the auditory-nerve I: Normal hearing kittens. Hearing Res. 1992;62(1):63-81.

23. Xu J, Shepherd RK, Millard RE, Clark GM. Chronic electrical stimulation of the auditory nerve at high stimulus rates: A physiological and histopathological study. Hear Res. 1997;105(1-2):1-29.

24. Kiefer J, Gstoettner W, Baumgartner W, Pok SM, Tillein J, Ye Q, von Ilberg $\mathrm{C}$. Conservation of low-frequency hearing in cochlear implantation. Acta Oto-Laryngol. 2004;124(3):272-80.

25. Fraysse B, Macias AR, Sterkers $O$, Burdo $S$, Ramsden R, Deguine $O$, Klenzner T, Lenarz T, Rodriguez MM, Von Wallenberg E, James C. Residual hearing conservation and electroacoustic stimulation with the nucleus 24 contour advance cochlear implant. Otol Neurootol. 2006;27(5):624-33.

26. Lenarz T, Stoever T, Buechner A, Lesinski-Schiedat A, Patrick J, Pesch J. Hearing Conservation Surgery Using the Hybrid-L Electrode Results from the First Clinical Trial at the Medical University of Hannover. Audiol Neurootol. 2009;14:22-31.

27. Gstoettner WG, Helbig S, Settevendemie C, Baumann U, Wagenblast J, Arnoldner C. A new electrode for residual hearing preservation in cochlear implantation: first clinical results. Acta Otolaryngol. 2009;129(4):372-9.

28. Gstoettner W, Kiefer J, Baumgartner WD, Pok S, Peters S, Adunka O. Hearing preservation in cochlear implantation for electric acoustic stimulation. Acta Otolaryngol. 2004;124(4):348-52.

29. Verbist BM, Ferrarini L, Briaire JJ, Zarowski A, Admiraal-Behloul F, Olofsen $\mathrm{H}$, Reiber JH, Frijns $\mathrm{JH}$. Anatomic Considerations of Cochlear Morphology and Its Implications for Insertion Trauma in Cochlear Implant Surgery. Otol Neurootol. 2009;30(4):471-7.

30. Eshraghi AA, Yang NW, Balkany TJ. Comparative study of cochlear damage with three perimodiolar electrode designs. Laryngoscope. 2003;113(3):415-9.

31. Simmons FB. The double-membrane break syndrome in sudden hearing loss. Laryngoscope. 1979;89(1):59-66.

32. Zenner HP. K+- induced motility and depolarization of cochlear hair-cells - direct evidence for a new pathophysiological mechanism in menieresdisease. Arch Oto-Rhino-Laryngology. 1986;243(2):108-11. 
33. Eshraghi AA, Polak M, He J, Telischl FF, Balkany TJ, Van De Water TR. Pattern of hearing loss in a rat model of cochlear implantation trauma. Otol Neurootol. 2005;26(3):442-7.

34. Campbell AP, Suberman TA, Buchman CA, Fitzpatrick DC, Adunka OF. Correlation of Early Auditory Potentials and Intracochlear Electrode Insertion Properties: An Animal Model Featuring Near Real-Time Monitoring. Otol Neurootol. 2010;31(9):1391-8.

35. Choi $\mathrm{CH}$, Oghalai JS. Predicting the effect of post-implant cochlear fibrosis on residual hearing. Hearing Res. 2005;205(1-2):193-200.

36. Glueckert R, Pfaller K, Kinnefors A, Rask-Andersen H, Schrott-Fischer A. The human spiral ganglion: New insights into ultrastructure, survival rate and implications for cochlear implants. Audiol Neurootology. 2005;10(5):258-73.

37. Somdas MA, Li P, Whiten DM, Eddington DK, Nadol JB. Quantitative evaluation of new bone and fibrous tissue in the cochlea following cochlear implantation in the human. Audiol Neurootol. 2007;12(5):27784.

38. Radeloff A, Shehata-Dieler W, Scherzed A, Rak K, Harnisch W, Hagen R, Mlynski R. Intraoperative Monitoring Using Cochlear Microphonics in Cochlear Implant Patients With Residual Hearing. Otol Neurootol. 2012;33(3):348-54.

39. Leake PA, Hradek GT, Snyder RL. Chronic electrical stimulation by a cochlear implant promotes survival of spiral ganglion neurons after neonatal deafness. J Comp Neurol. 1999;412(4):543-62.

40. Khan AM, Handzel O, Eddington DK, Damian D, Nadol JB. Effect of cochlear implantation on residual spiral. ganglion cell count as determined by comparison with the contralateral nonimplanted inner ear in humans. Ann Otol Rhinol Laryngol. 2005;114(5):381-5.

41. Helbig S, Baumann U, Hey C, Helbig M. Hearing preservation after complete cochlear coverage in cochlear implantation with the free-fitting Flexsoft electrode carrier. Otol Neurootol. 2011;32(6):973-9.

42. Lehnhardt E. Intracochlear placement of cochlear implant electrodes in soft surgery technique. HNO. 1993;41(7):356-9.

43. Briggs RJS, Tykocinski M, Stidham K, Roberson JB. Cochleostomy site: Implications for electrode placement and hearing preservation. Acta Otolaryngol. 2005;125(8):870-6.

44. Adunka O, Kiefer J. Impact of electrode insertion depth on intracochlear trauma. Otolaryngol Head Neck Surg. 2006;135(3):374-82.

45. Briggs RJ, Tykocinski M, Xu J, Risi F, Svehla M, Cowan R, Stover T, Erfurt P, Lenarz T. Comparison of round window and cochleostomy approaches with a prototype hearing preservation electrode. Audiol Neurootol. 2006;11(Suppl 1):42-8. 
46. Roland PS, Wright CG, Isaacson B. Cochlear implant electrode insertion: The round window revisited. Laryngoscope. 2007;117(8):1397-402.

47. Meshik X, Holden TA, Chole RA, Hullar TE. Optimal cochlear implant insertion vectors. Otol Neurootol. 2010;31(1):58-63.

48. Adunka OF, Radeloff A, Gstoettner WK, Pillsbury HC, Buchman CA. Scala tympani cochleostomy II: topography and histology. Laryngoscope. 2007;117(12):2195-200.

49. Roland PS, Wright CG. Surgical aspects of cochlear implantation: mechanisms of insertional trauma. Adv Otorhinolaryngol. 2006;64:11-30.

50. Jiang D, Fitzgerald O'Connor A. The assessment of the access to the round window via a posterior tympanotomy: a pratical classification. $26^{\text {th }}$ Politzer Society Meeting; 2007; Cleveland.

51. Li PM, Wang H, Northrop C, Merchant SN, Nadol JB, Jr. Anatomy of the round window and hook region of the cochlea with implications for cochlear implantation and other endocochlear surgical procedures. Otol Neurootol. 2007;28:641-8.

52. Shapira Y, Eshraghi AA, Balkany TJ. The perceived angle of the round window affects electrode insertion trauma in round window insertion - an anatomical study. Acta Otolaryngol. 2011;131(3):284-9.

53. Nguyen Y, Miroir M, Kazmitcheff G, Sutter J, Bensidhoum M, Ferrary E, Sterkers O, Bozorg Grayeli A. Cochlear Implant Insertion Forces in Microdissected Human Cochlea to Evaluate a Prototype Array. Audiol Neurootol. 2012;17:290-8.

54. Kirkwood BR, Sterne JAC. Essential medical statistics. 2nd ed. Massachusetts: Blackwell Science; 2006.

55. Shahidullah S, Hepper PG. Hearing in the fetus: Prenatal detection of deafness. Int J Prenatal Perinatal Stud. 1992;4:235-40.

56. Arts HA, Garber A, Zwolan TA. Cochlear implants in young children. Otolaryngol Clin North Am. 2002;35(4):925.

57. Sampaio AL, Araujo MF, Oliveira CA. New criteria of indication and selection of patients to cochlear implant. Int $\mathrm{J}$ Otolaryngol. 2011;2011:573968.

58. Lenarz T. Cochlear implants: selection criteria and shifting borders. Acta Otorhinolaryngol Belg. 1998;52(3):183-99.

59. Gomaa NA, Rubinstein JT, Lowder MW, Tyler RS, Gantz BJ. Residual speech perception and cochlear implant performance in postlingually deafened adults. Ear Hear. 2003;24(6):539-44.

60. Adunka OF, Buss E, Clark MS, Pillsbury HC, Buchman CA. Effect of preoperative residual hearing on speech perception after cochlear implantation. Laryngoscope. 2008;118(11):2044-9. 
61. Turner CW, Gantz BJ, Vidal C, Behrens A, Henry BA. Speech recognition in noise for cochlear implant listeners: Benefits of residual acoustic hearing. J Acoust Soc Am. 2004;115(4):1729-35.

62. Gantz BJ, Turner C, Gfeller KE. Acoustic plus electric speech processing: preliminary results of a multicenter clinical trial of the lowa/Nucleus Hybrid implant. Audiol Neurootol. 2006;11(Suppl 1):63-8.

63. Turner C, Gantz BJ, Reiss L. Integration of acoustic and electrical hearing. J Rehabil Res Dev. 2008;45(5):769-78.

64. Gantz BJ, Hansen MR, Turner CW, Oleson JJ, Reiss LA, Parkinson AJ. Hybrid 10 Clinical Trial Preliminary Results. Audiol Neurootol. 2009;14:32-8.

65. Turner CW, Gantz BJ, Karsten S, Fowler J, Reiss LA. Impact of hair cell preservation in cochlear implantation: combined electric and acoustic hearing. Otol Neurootol. 2010;31(8):1227-32.

66. Gfeller KE, Olszewski C, Turner C, Gantz B, Oleson J. Music perception with cochlear implants and residual hearing. Audiol Neurootol. 2006;11(Suppl 1):12-5.

67. Berrettini S, Forli F, Passetti S. Preservation of residual hearing following cochlear implantation: comparison between three surgical techniques. $J$ Laryngol Otol. 2008;122(3):246-52.

68. Takahashi H, Sando I. Computer-aided 3-d temporal bone anatomy for cochlear implant-surgery. Laryngoscope. 1990;100(4):417-21.

69. Chen BK, Clark GM, Jones R. Evaluation of trajectories and contact pressures for the straight nucleus cochlear implant electrode array - a two-dimensional application of finite element analysis. Med Engin Phys. 2003;25(2):141-7.

70. Kennedy DW. Multichannel intracochlear electrodes - mechanism of insertion trauma. Laryngoscope. 1987;97(1):42-9.

71. Plenk $\mathrm{H}$. The microscopic evaluation of hard tissue implants. In: Williams $\mathrm{D}$, editor. Techniques of biocompability testing. Boca Raton: CRC Press; 1986. p.35-81.

72. Gstoettner W, Franz P, Hamzavi J, Plenk H, Baumgartner W, Czerny C. Intracochlear position of cochlear implant electrodes. Acta Oto-Laryngol. 1999;119(2):229-33. 
APÊNDICES 


\title{
APÊNDICE 1
}

\section{CARTA DE APROVAÇÃO DO COMITÊ DE ÉTICA EM PESQUISA DA FMUSP}

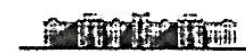 \\ MEDICINA \\ TSP \\ COMITÊ DE ÉTICA EM PESQUISA
}

O Comitê de Ética em Pesquisa da Faculdade de Medicina da Universidade de São Paulo, em sessão de 15.09.10, APROVOU o Protocolo de Pesquisa $\mathrm{n}^{\mathrm{o}} \mathbf{2 6 2 / 1 0}$ intitulado: "Estudo do Trauma Intracoclear pela Inserção do Feixe de Eletrodos de Implante Coclear na Janela Redonda de Ossos Temporais" e seus anexos, apresentado pelo Departamento de Otorrinolaringologia.

Cabe ao pesquisador elaborar e apresentar ao CEP-FMUSP, os relatórios parciais e final sobre a pesquisa .

Pesquisador (a) Responsável: Ricardo Ferreira Bento

Pesquisador (a) Executante: Graziela de Souza Queiroz Martins

CEP-FMUSP, 15 de setembro de 2010.

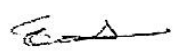

Prof. Dr. Eduardo Massad

Coordenador

Comitê de Ética em Pesquișa

Comitê de Ética em Pesquisa da Faculdade de Medicina da Universidade de São Paulo Rua .Ovídio Pires de Campos, 225, $5^{\circ}$ andar - CEP 05403010 - São Paulo - SP Fone: 01130696442 Fax: 01130696492 e-mail: cep. fmuspourhenet.usp.br 


\title{
APÊNDICE 2
}

\section{ADENDO AO PROTOCOLO DO COMITÊ DE ÉTICA EM PESQUISA DA FMUSP}

\author{
AIIIIII \\ MEDICINA \\ एTSP \\ COMITÊ DE ÉTICA EM PESQUISA
}

\section{APROVAÇÃO}

O Comitê de Ética em Pesquisa da Faculdade de Medicina da Universidade de São Paulo, em de 23 de Março de 2012, APROVOU o(s) documento(s) abaixo mencionado(s) no Protocolo de Pesquisa $n^{\circ}$ 262/10, intitulado: “ESTUDO DO TRAUMA INTRACOCLEAR PELA INSERÇÃO DO FEIXE DE ELETRODOS DE IMPLANTE COCLEAR NA JANELA REDONDA DE OSSOS TEMPORAIS" apresentado pelo OFTALMOLOGIA E OTORRINOLARINGOLOGIA.

-Adendo informando que o projeto será realizado com peças de cadáver conforme documento anexo.

Pesquisador (a) Responsável: Prof. Dr. Ricardo Ferreira Bento

CEP-FMUSP, 23 de Março de 2012

$$
\text { pllatumn. }
$$

Prof. Dr. Roger Chammas Coordenador

Comitê de Ética em Pesquisa 


\section{APÊNDICE 3}

\section{APROVAÇÃO NOS RESPECTIVOS DEPARTAMENTOS DA FMUSP}

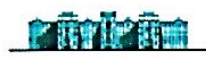

MEDICINA

एत्ग

Departamento de Radiologia

Av. Dr. Enéas de Carvalho Aguiar, $255-3^{\circ}$ andar - sala 2.11

CEP 05403-000

São Paulo - SP - Brasil

Fone/Fax: (11) 2661-7064

DR APROVAÇÃO 065/2012

APROVAÇÃO

O Conselho do Departamento de Radiologia aprovou, em 21/11/2012, o projeto de pesquisa:

TíTULO: "Estudo do trauma intracoclear na inserção do feixe de eletrodos de implante coclear pela janela redonda de ossos temporais"

Pesquisador responsável: Dr. Ricardo Ferreira Bento

Pesquisador executante: Graziela de Souza Queiroz

Finalidade: DOUTORADO

São Paulo, 21 de novembro de 2012

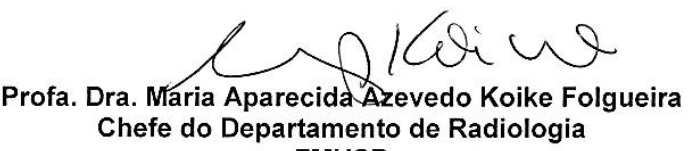
FMUSP 